\title{
Buildings as a global carbon sink? The design of mass timber panels as heat-exchangers (dynamic insulation)
}

Salmaan Craiga,*, Anna Halepaska ${ }^{\mathrm{b}}$, Jacob Elbrecht ${ }^{\mathrm{b}}$, Katherine Ferguson ${ }^{\mathrm{b}}$, Preston Rains $^{\mathrm{b}}$, Andrew Freear $^{\mathrm{b}}$, David Kennedy ${ }^{\mathrm{b}}$, Kiel Moe ${ }^{\mathrm{a}}$

${ }^{a}$ School of Architecture, Faculty of Engineering, McGill University, Montreal, Quebec, Canada

${ }^{b}$ Rural Studio, School of Architecture, Auburn University, Newbern, Alabama, USA

\section{Abstract}

Mass timber products, together with careful forestry management, could help decarbonize the construction industry. These products must be long-lasting, to safely store atmospheric carbon for decades or centuries, and multi-functional, to displace materials and equipment that are emissions-intensive. This paper shows how to optimize mass timber panels as heat-exchangers, suggesting how to eliminate insulation while simplifying HVAC systems. Test panels measured the heat-exchange in steady and transient conditions, when the ventilation was driven by a fan or by thermal buoyancy. The total heatexchange was predicted accurately by theory in all cases. Further investigation is needed to understand the possible heat-recovery effects at the exterior surface.

Keywords: Dynamic insulation, Heat-exchangers, Mass timber, Low carbon, Carbon utilization, Thermally active surfaces

\section{Introduction}

Building operations are responsible for $28 \%$ of greenhouse gas (GHG) emissions, while $11 \%$ of emissions come from construction activities, mainly the production of building materials such as cement and steel [1]. In the coming decades, the growth and urbanization of the global population will create a vast demand for new buildings

\footnotetext{
*Corresponding author.

Email address: salmaan.craig@mcgill.ca (Salmaan Craig)
}

and infrastructure. 'Embodied' emissions from the construction sector are therefore set to rise sharply, just as global emissions need to drastically fall [2]. Is it possible to transform this potential threat to the global climate system into a powerful means to mitigate climate change?

\subsection{Carbon utilization}

There is a growing likelihood that meeting climate goals will require carbon removal techniques, also known as 'negative emissions'. Scientists and practitioners are starting to recognize 
the potential of new buildings as a global carbon sink [3]. There is a range of materials that can store $\mathrm{C}$ or $\mathrm{CO}_{2}$, but only two that are in widespread use in the construction industry today. Wood grows by photosynthesis and timber products may count as sequestered carbon if the forests are well-managed and the products are long-lived. The concrete curing process can be tailored to absorb more $\mathrm{CO}_{2}$ while the $\mathrm{CO}_{2}$ from producing cement can be mineralized in the flue and used as aggregate. According to a recent analysis, timber and concrete could each store $\sim 0.5$ Gt $\mathrm{CO}_{2}$ annually assuming there is proper coordination of their production cycles [4]. These potential quantities put new buildings on par with other front-runners for utilizing atmospheric carbon in the technosphere.

Design integration can multiply these potential savings. For instance, if mass timber structures can actively produce interior climates using only low-grade heat, there will be less need for extra materials and mechanical systems. The metric for multiplying GHG reductions through functional substitution is known as the 'displacement factor' [5-7]. For $\mathrm{CO}_{2}$ utilization to reach its full potential, however, carbon-storing materials must do more than replace conventional materials in a piecemeal fashion. The materials must perform as many functions as possible, so they can displace entire systems that are emissions-intensive.

\subsection{Radical integration}

What advances in materials engineering could deliver this kind of radical integration? 'Designed porous media' are materials shaped internally and externally to exchange heat and mass [8]. Like 'Architecture-d materials' [9] and 'Form-active structures' [10], the innovative aspect is how the morphology of the material manages the flow of energy. Applying these new methods may be the key to upgrading carbon-storing building materials. Not only to enhance their structural performance, but to integrate thermal and ventilation functions, so extra materials and mechanical systems are less necessary.

One example is designing mass timber panels as heat exchangers or 'breathing walls.' The principle is to introduce air-channels into the solid and to optimize their size and spacing, so the outgoing conduction heats the incoming air. This technique could make insulation and cladding materials redundant while helping to simplify HVAC systems. Figure 1 explains the heat exchange concept, and the principle for optimizing the geometry. Craig and Grinham used physical experiments to validate a correlation for optimizing heat-exchanging materials [11]. The design correlation was originally developed by other researchers [12] for extreme thermal conditions, but Craig and Grinham's results show that it works for building materials in ambient conditions, too. This paper is a follow-up to their work. It exam- 
ines how to apply the correlation and the design principles to mass timber panels. 'Mass timber' refers to engineered wood products, laminated from smaller boards into structural components, such as glue-laminated (glulam) beams or crosslaminated timber (CLT) panels.

\subsection{Dynamic Insulation}

Designing a construction material as a heatexchanger makes it a kind of Dynamic Insulation (DI) technology. DI began as a novel ventilation strategy for agricultural buildings in cold climates. Engineers described how to suck fresh air through a layer of fibrous insulation, reducing conduction losses while simultaneously heating the air [13]. In the early nineties, researchers installed DI in a residential unit in Japan and reported a $50 \%$ reduction in thermal envelope losses [14]. Soon after, two significant advances in DI theory followed. Taylor and Imbabi developed a simple analytical model to describe steady heat exchange in DI when the interior surface temperature or rate of surface convection is known [1519]. Krarti developed a detailed analytical model to incorporate thermal storage effects and show the impact of periodic changes in the exterior environment [20].

There has been a renewed interest in the theory, measurement, and design of DI systems in recent years. A group from Politecnico di Milano has described the microscopic heat-exchange effects in fibrous insulation and developed an appa- ratus for testing DI panels $[21,22]$. They used the apparatus to validate the heat exchange behavior in steady and periodic conditions compared to simple and detailed analytical models [23-25]. A group from Huazhong University has developed a finite-difference model and an apparatus for DI testing [26-28]. Their work shows how to eliminate envelope gains in the summer by forcing exhaust air out through the insulation. Krarti and numerous collaborators have developed DI control strategies and defined the potential energy savings for 'switchable' U-values in various contexts [2934]. Instead of using a porous material as a heat exchanger, they designed partitions that can be opened or closed to control convection inside a sealed panel.

\subsection{Why wood?}

Craig and Grinham showed how to introduce air channels into standard construction materials and optimize them for heat-exchange [11]. This new capability suggests a different way of building, better suited to the challenges of carbon removal. Instead of building a structure and cladding it with layers of specialized materials, it may be possible to combine all primary functions into one material. But which material? As discussed, both concrete and timber have the potential to store carbon at a global scale $[3,4]$. There are significant challenges to overcome in each case. For instance, carbonates stay locked in concrete for centuries and release only in extremely acidic 

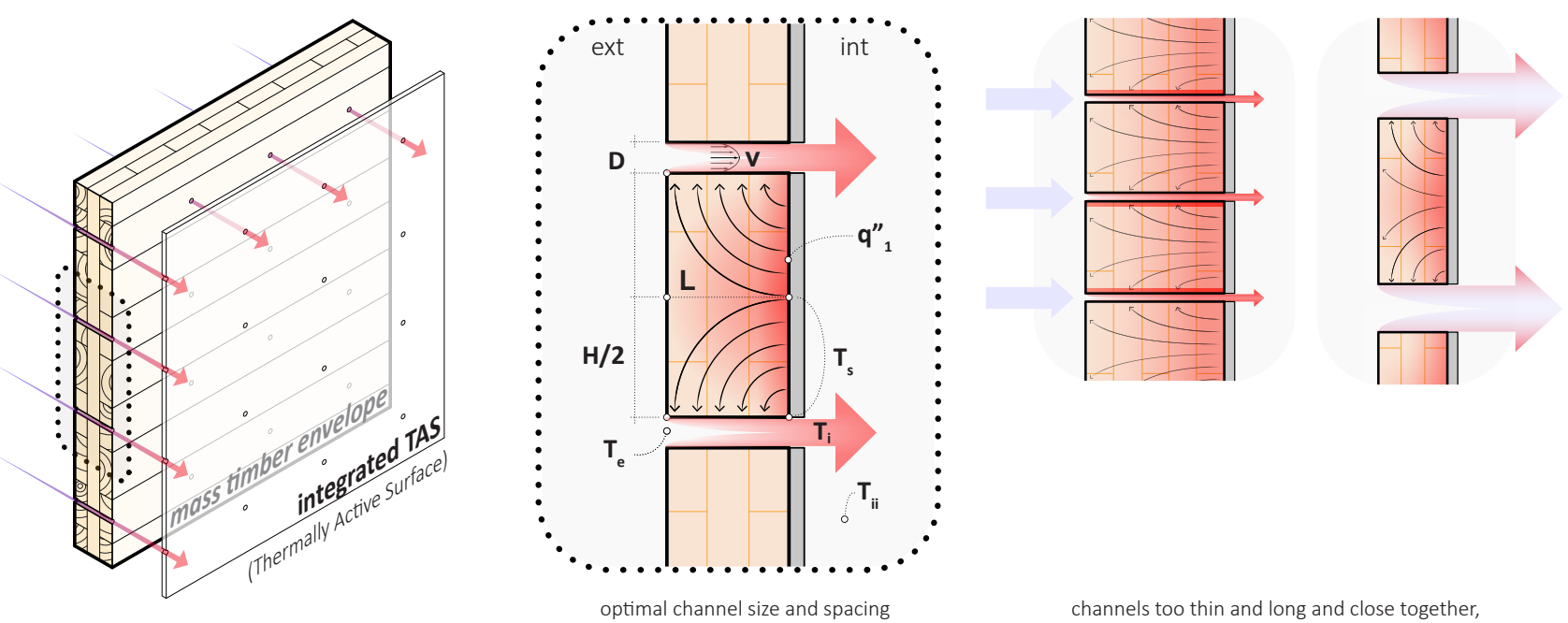

channels too thin and long and close together, or too fat and short and far apart

Figure 1: How to optimize the size and spacing of channels to design a mass timber panel as a heat-exchanger. Kim, Lorente, and Bejan developed the design correlations for aerospace applications [12]. Craig and Grinham showed they worked for building materials [11]. This study applies them to mass timber.

conditions. In contrast, the likelihood of $\mathrm{CO}_{2}$ release is higher for wood products, which can decompose or combust.

Obstacles notwithstanding, both material supply chains and product life cycles need a fundamental overhaul, and there is essential research to be done in both areas. The focus of this study is timber, because its thermal properties make it better suited for the proposed method of heatexchange. Figure 2 compares the steady heatexchange of two panels, one wood, one concrete. Both are optimal, designed for the same relative rate of heat-exchange. However, the concrete panel is not feasible because the absolute heating requirements and thermal losses are too high.
The reason is the thermal conductivity of concrete, which is tenfold higher than wood (see Figure 6 in section 4). The low thermal conductivity of timber makes it unique compared to other structural materials. Not only can it store carbon and support a building, but it can also meet stringent standards for conduction losses without overventilating or overheating.

\subsection{Boundary conditions}

One longstanding question in DI research with porous materials is what boundary conditions to assume in modeling. Field experiments have shown lower than predicted temperatures at the interior surface, with negative implications for 


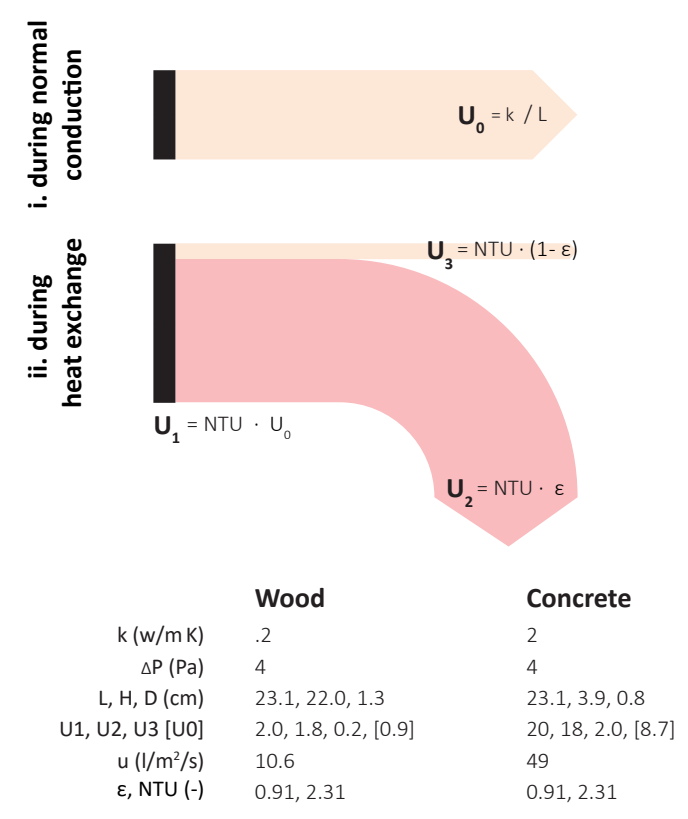

Figure 2: The heat-exchange principle shown in Figure 1, depicted as a sankey. Mass timber is better suited than concrete for this application. Wood has a lower thermal conductivity, so it is possible to reduce conduction losses $\left(U_{3}\right)$ without overventilating $\left(U_{2}\right)$ or overheating $\left(U_{1}\right)$.

thermal comfort and energy savings [14].

How does the convection boundary film behave at the interior surface? This question is essential for DI research because porous materials must receive heat from the room before they can exchange it to the incoming air. Using Schlieren imaging, Craig and Grinham found that porous materials lose thermal contact with the room air when the incoming air lifts the boundary film off the interior surface [11]. They found subtle effects at the exterior surface, too. Convection heat transfer was multiplied several-fold, and the heat in the boundary film was sucked back into the material. They concluded there was potential for heat recovery at the exterior surface, and that it was best to heat the interior surface by direct contact.

Following this recommendation, the test panels in the present study are directly heated at the interior surface. Not much heating is required. For instance, the wood panel example in Figure 2 only needs $U_{1}=2\left(\mathrm{~W} / \mathrm{m}^{2} . K\right)$, which is in the range of standard underfloor heating. Electric resistance heating was used in the present study as this was practical given the available resources. Craig and Grinham fabricated a custom hydronic panel to heat their test panels. Standard capillary tubing would also work for direct contact heating. For future applications, hydronic circuits are preferable. Heating or cooling technologies that use large exchange surfaces inside rooms are called radiant systems or thermally-active surfaces (TAS) [35-37]. A large TAS, with a watercircuit connected to a 'low-lift' heat pump, can make use of small temperature differences from renewable sinks and sources, such as solar, geothermal, and the infrared sky [38, 39].

\subsection{Natural ventilation}

If hydronic surfaces are ideal for monomaterial heat-exchanging envelopes, are there other opportunities for integrating HVAC functions? Natural ventilation has an essential role in minimizing HVAC infrastructure and its lifecycle emissions [40]. Significant advances have been made in understanding the fluid mechanics of buoyancy 
ventilation, which is driven by heat, not wind. For example, one breakthrough came in 2009, when researchers characterized an automatic heat recovery mechanism known as 'natural mixing' [41]. As warm air rises and exits, fresh air replaces it, falling through the same opening. The outgoing air preheats the incoming air in a state of dynamic equilibrium.

Some researchers have examined the possibility of coupling DI with natural ventilation [42-44]. The coupling can be enhanced by using monomaterial, heat-exchanging envelopes (i.e. 'breathing walls'). By harnessing the buoyancy effect, all heat and air exchanges can be controlled by the integrated hydronic surface. Figure 3 shows two possibilities. On the left-hand side, buoyancy powers the ventilation but there is no heat recovery at the exhaust. The right-hand side shows a hypothesis for how to recover ventilation at the exhaust using a double shell. This article does not examine natural heat-recovery loops. However, it makes a significant step by showing it is feasible to couple breathing walls with buoyancy ventilation in a controllable way.

\subsection{Outlook}

This paper reports the results of three experiments, which characterize the behavior of mass timber panels that are optimized as heatexchangers. An app is provided so readers can evaluate possible designs for themselves [45]. The first experiment measures the heat-exchange in steady-state and the time to reach steady-state when panels are subjected to a step-change in heating. The second experiment shows how the heat-exchange varies periodically with daily changes in the exterior temperature. The final experiment shows it is possible to suck ventilation through the panels using thermal buoyancy instead of a fan, while maintaining the expected rates of heat-exchange.

\section{Theory}

\subsection{Steady heat-exchange}

Figure 1 illustrates the principle of how to optimize parallel channels in a solid material for 'contra-flux' heat-exchange. Kim, Lorente, and Bejan developed two numerical correlations for this scenario [12]. Craig and Grinham validated the correlations experimentally [11]. The first correlation gives the optimum spacing of the channels:

$$
\frac{H_{o p t}}{L}=3.22 B e^{-1 / 3} \Phi^{-0.85}\left(\frac{k}{k_{a}}\right)^{0.17}
$$

where $H_{o p t}$ is the optimized channel spacing, $L$ is the panel thickness, $k$ is the thermal conductivity of the panel material, and $k_{a}$ is the thermal conductivity of the air. The Bejan number, Be, is defined as:

$$
B e=\frac{\Delta P L^{2}}{\mu \alpha}
$$

where $\Delta P$ is the design pressure, $\mu$ is the dynamic viscosity of the air, and $\alpha$ is the thermal diffusivity 

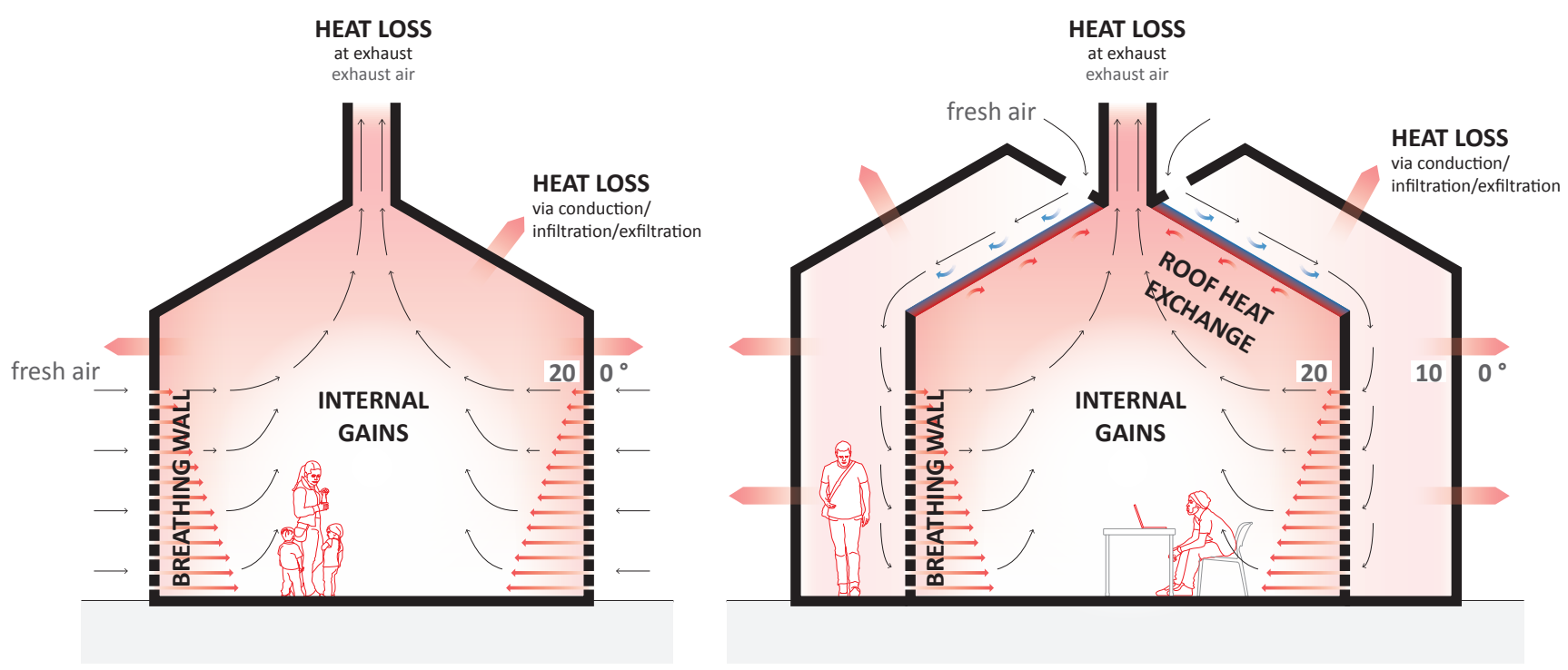

Figure 3: Towards monomaterial buildings? How to couple 'breathing walls' with buoyancy ventilation. Left: Buoyancy powers the ventilation but there is no heat recovery at the exhaust. Right: Hypothesis for how to recover ventilation at the exhaust using a double shell.

of the air. The void fraction of the panel, $\Phi$, is defined as:

$$
\Phi=\frac{\pi D^{2}}{4 H^{2}}
$$

where $D$ is the diameter of the channels.

The second correlation predicts the total heat transfer through the optimal design:

$$
N T U=0.41 B e^{1 / 3} \Phi^{0.6}\left(\frac{k}{k_{a}}\right)^{-0.65}
$$

The Number of Thermal Units, NTU, is the ratio of the total heat transfer coefficient during heat-exchange, $U_{1}$, to the baseline condition when there is no heat-exchange, $U_{0}$ :

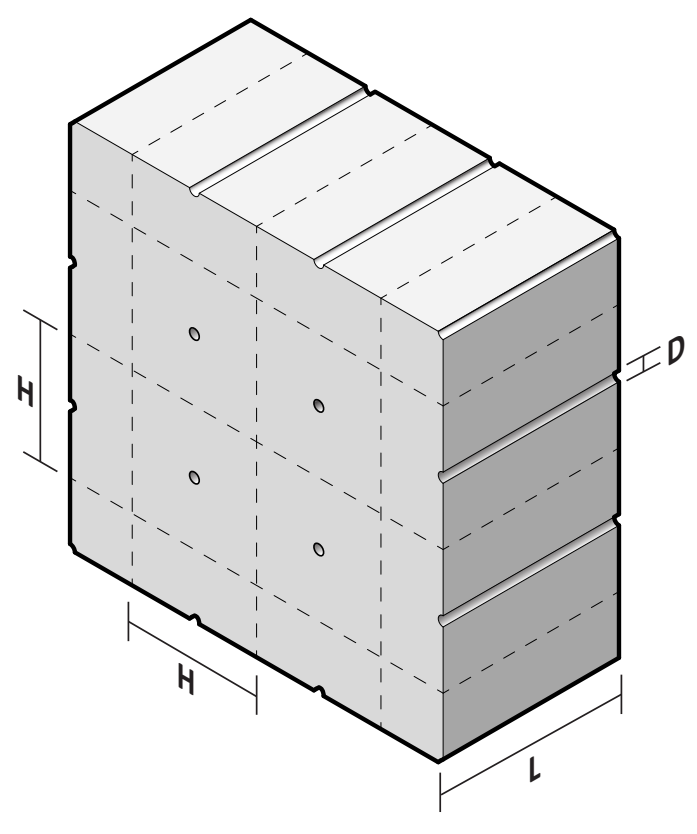

$$
N T U=\frac{U_{1}}{U_{0}}=\frac{q_{1}^{\prime \prime} /\left(T_{s}-T_{e}\right)}{k / L}
$$

Figure 4: Geometry definition 
where $q_{1}^{\prime \prime}$ is the heat flux at the heated interior surface, $T_{s}$ is the temperature of the heated interior surface, and $T_{e}$ is the temperature of the exterior air (which enters through the channels). During sensible, steady heat-exchange, the surface heat flux $\left(q_{1}^{\prime \prime}\right)$ transfers in part to the incoming air $\left(q_{2}^{\prime \prime}\right)$ while the remainder $\left(q_{3}^{\prime \prime}\right)$ is lost to the exterior environment by conduction:

$$
q_{1}^{\prime \prime}=q_{2}^{\prime \prime}+q_{3}^{\prime \prime}
$$

Figure 2 illustrates this heat-exchange balance, which can also be defined in terms of coefficients of heat transfer:

$$
U_{1}=U_{2}+U_{3}
$$

where:

$$
\begin{aligned}
& U_{1}=\frac{q_{1}^{\prime \prime}}{\left(T_{s}-T_{e}\right)}=N T U U_{0} \\
& U_{2}=\frac{q_{2}^{\prime \prime}}{\left(T_{s}-T_{e}\right)}=\varepsilon N T U U_{0} \\
& U_{3}=\frac{q_{3}^{\prime \prime}}{\left(T_{s}-T_{e}\right)}=(1-\varepsilon) N T U U_{0}
\end{aligned}
$$

and $\varepsilon$ is the heat-exchange efficiency:

$$
\varepsilon=1-e^{-N T U}
$$

These definitions of $\varepsilon$ and NTU are valid so long as the surface heat flux $\left(q_{1}^{\prime \prime}\right)$ or the surface temperature $\left(T_{s}\right)$ are constant and uniform. Integrated hydronics can closely approximate both boundary conditions [11]. In either condition, $\varepsilon$ is equivalent to the relative temperature increase experienced by the incoming air:

$$
\varepsilon=\frac{T_{i}-T_{e}}{T_{s}-T_{e}}
$$

where $T_{i}$ is the temperature of the incoming air at the moment it leaves the channels and enters the interior space. Note that as $\varepsilon \rightarrow 1, T_{i} \rightarrow T_{s}$

Following the convention in the dynamic insulation literature, $U_{3}$ in Equation (10) can be referred to as the 'dynamic U-value'. However, it is important to emphasize the balance expressed in Equation (7) and illustrated in Figure 2. That is, achieving low values for $U_{3}$ should not come at the expense of over-ventilating $\left(U_{2}\right)$ or overheating $\left(U_{1}\right)$. The air flow rate per unit area of panel is defined as:

$$
u=\frac{D^{2} \Phi \Delta P}{32 \mu L}
$$

and has units of $\mathrm{m} / \mathrm{s}$ or $\mathrm{m}^{3} / \mathrm{m}^{2} / \mathrm{s}$. Finally, there is an important sizing limit to take note of:

$$
\frac{H}{L}<2
$$

Equation (1) and Equation (4) are invalid if this limit is exceeded. The panel is too thin relative to the channel spacing. Physically, there is not enough space for the heat to bend towards the channels, as illustrated on the right-hand side of Figure 1. (Heat only conducts to lower temperatures so bending the flux more than $90^{\circ}$ would contravene the second law of thermodynamics.)

The equations above describe the steady heatexchange in optimized panels. What are the design implications for mass timber? Figure 5 shows 

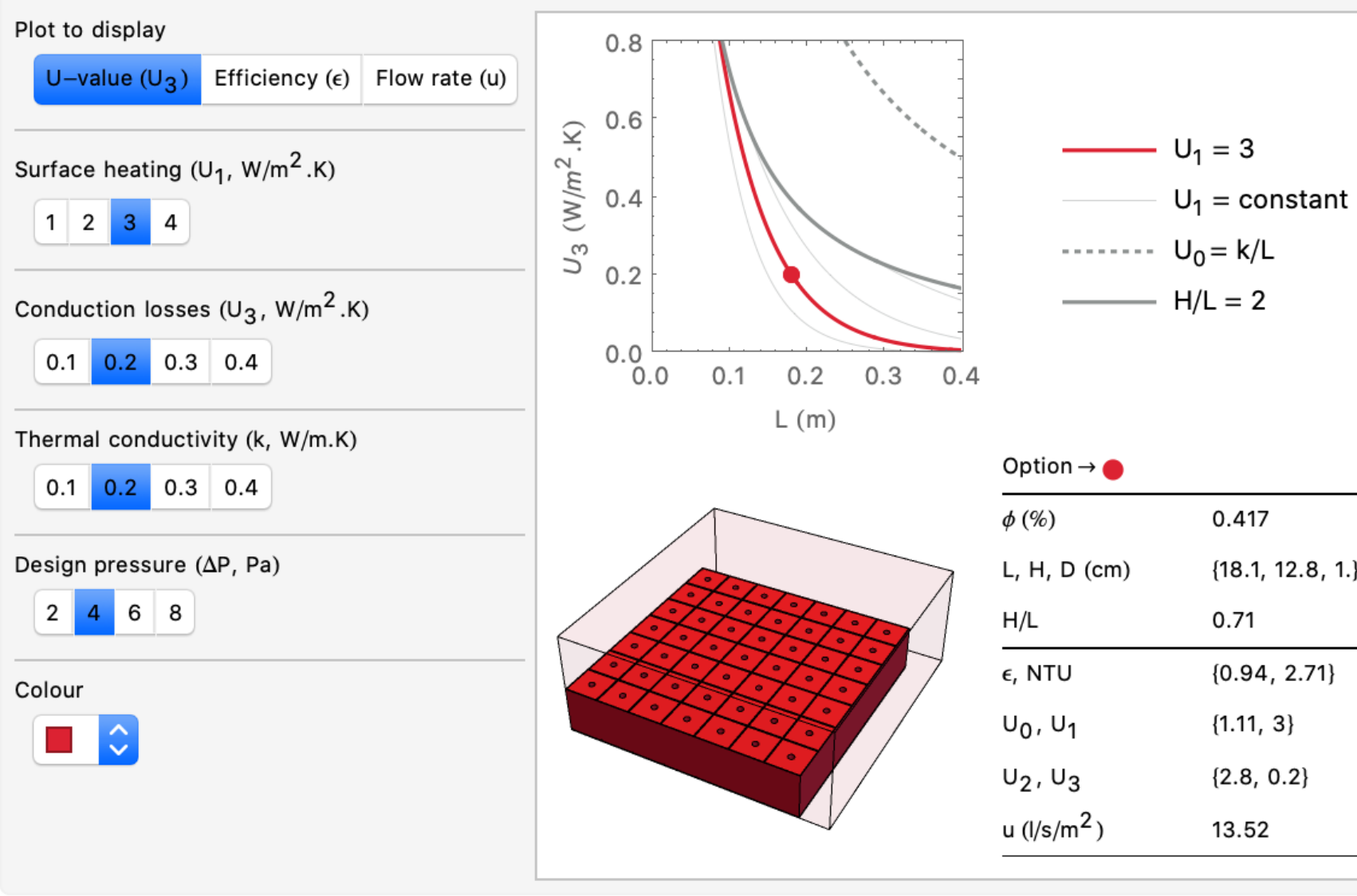

Option $\rightarrow \mathrm{O}$

\begin{tabular}{ll}
\hline$\phi(\%)$ & 0.417 \\
$\mathrm{~L}, \mathrm{H}, \mathrm{D}(\mathrm{cm})$ & $\{18.1,12.8,1\}$. \\
$\mathrm{H} / \mathrm{L}$ & 0.71 \\
\hline$\epsilon, \mathrm{NTU}$ & $\{0.94,2.71\}$ \\
$\mathrm{U}_{0}, \mathrm{U}_{1}$ & $\{1.11,3\}$ \\
$\mathrm{U}_{2}, \mathrm{U}_{3}$ & $\{2.8,0.2\}$ \\
$\mathrm{u}\left(\mathrm{I} / \mathrm{s} / \mathrm{m}^{2}\right)$ & 13.52 \\
\hline
\end{tabular}

Figure 5: A screenshot of an app, written to partner this article, and free to download here [45]. It solves equations 1-14, showing how to optimize mass timber panels as heat-exchangers.

a screenshot of an app that is free to download and which solves the above equations to help evaluate options for optimzing mass timber panels as heat-exchangers [45]. The app has four control parameters. Designers can choose values for each parameter from a specified range (it is straightforward to adjust these ranges by changing the source code):

- The thermal conductivity $k(W / m . K)$ of the base material. The range $0.1<k<$ 0.4 was chosen to encompass most softwood and hardwood species, irrespective of grain orientation (see Figure 6 ).

- The conduction heat loss coefficient, i.e. $U_{3}\left(W / m^{2} . K\right)$ the 'dynamic U-value'. The range $0.1<U_{3}<0.4$ was chosen to represent mandatory $\mathrm{U}$-value standards in different countries and climates as well as voluntary standards like Passivhaus.

- The surface heating coefficient $U_{1}\left(\mathrm{~W} / \mathrm{m}^{2} . K\right)$ (which can be controlled by integrated hydronic heating). The range $1<U_{1}<4$ is deliberately low, similar to standard underfloor heating. (Recall that it is pointless 
having low conduction losses if achieving this target requires too much heat input)

- The design pressure, $\triangle P(P a)$ which is imposed on the panel by suction. The range $2<\triangle P<8$ was chosen because these pressures are feasible to sustain mechanically using a fan or naturally using thermal buoyancy (the stack effect).

Table 1 compares three potential designs for heat-exchanging mass timber panels, computed using the app. All three hypothetical cases achieve the same low 'dynamic U-value', $U_{3}=$ $0.2 \mathrm{~W} / \mathrm{m}^{2} . K$, which is in range of U-values mandated by stringent energy efficiency codes. The differences between the design options stem from the surface heating, which varies by small increments $\left(U_{1}=2,3,4 \mathrm{~W} / \mathrm{m}^{2} . K\right)$. The panels get thinner as the surface heating increases $(L \approx 23,18,15 \mathrm{~cm})$. Note that these thicknesses are in the range of standard thicknesses for CLT panels. The other change is to the airflow rate per unit panel area, which increases $\left(u \approx 10,14,16 \mathrm{l} / \mathrm{s} / \mathrm{m}^{2}\right)$ as the panels get thinner. These rates mean that approximately one square meter of panel meets the ventilation needs of one person. For context, international standards recommend a ventilation rates $\sim 10 \mathrm{l} / \mathrm{s}$ per person in an office environment, though adverse effects to health or productivity have been documented when the rate is as high as $25 \mathrm{l} / \mathrm{s}$ per person [46].

\subsection{Transient heat-exchange}

The performance of timber panels in steady heat-exchange is promising, but how long do they take to reach steady-state, and how does the diurnal variation in exterior temperature influence the heat-exchange?

Krarti's model describing the transient behavior of dynamic insulation was recently validated in controlled, periodic conditions [20, 25]. However, this model is for heat exchange in one spatial dimension. It is suitable for fibrous or openpore insulation materials in contra-flux but does not apply to materials where the conduction flux varies in two or three spatial dimensions, as illustrated in Figure 1. The basis for the 'breathing wall' principle shown in Figure 1 is a study by Kim, Lorente, and Bejan which showed how to optimize parallel channels for steady heat exchange in extreme thermal conditions [12]. They extended their work by optimizing tree-shaped channels in steady-state then by characterizing the transient response to sudden heating [47, 48]. However, their transient analysis only applies to tree-shaped channels.

\subsubsection{Time to steady-state}

It seems there is no model available in the literature to describe transient contra-flux heatexchange in a panel with parallel channels. The thermal response can instead be approximated as 
Table 1: Three example options for timber heat-exchange panels, each optimized for $U_{3}=0.2 \mathrm{~W} / \mathrm{m}^{2} . K$

\begin{tabular}{llll}
\hline & $\# 1$ & $\# 2$ & $\# 3$ \\
\hline$k(W / m . K)$ & 0.2 & 0.2 & 0.2 \\
$\triangle P(P a)$ & 4.0 & 4.0 & 4.0 \\
$U_{0}, U_{1}, U_{2}\left(W / m^{2} . K\right)$ & $0.9,2.0,1.8$ & $1.1,3.0,2.8$ & $1.3,4.0,3.8$ \\
$L, H, D(\mathrm{~cm})$ & $23.1,22.0,1.3$ & $18.1,12.8,1.0$ & $15.0,8.8,0.8$ \\
$u\left(l / s / m^{2}\right)$ & 10.6 & 13.5 & 16.1 \\
$\varepsilon, N T U(-)$ & $0.91,2.31$ & $0.94,2.71$ & $0.95,3.0$ \\
\hline
\end{tabular}

a function of the Fourier number:

$$
F_{O}=\frac{\alpha t}{L_{c}^{2}}
$$

where $\alpha$ is the thermal diffusivity of the material, $t$ is the time in seconds, and $L_{c}$ is the characteristic length, defined as the ratio of the solid's volume to exposed surface area which, for the geometry defined in Figure 4, is:

$$
L_{c}=\frac{\left(H^{2}-\frac{\pi D^{2}}{4}\right) L}{2\left(H^{2}-\frac{\pi D^{2}}{4}\right)+\pi D L}
$$

The Fourier number is a measure of time without units. It is a ratio where 1 signifies that heat has penetrated the entire depth of the object. The thermal response of a 'breathing wall' to a stepchange in surface temperature or surface heat-flux can now be characterized as:

$$
N T U(t)=\left(a_{1} N T U+\frac{a_{2}}{\sqrt{F_{O}}}\right) \frac{L}{L_{c}}
$$

where $N T U$ is the steady-state design value defined by Equation (4) and $a_{1}$ and $a_{2}$ are empirical coefficients. Recall that the 3D evolution of the heat-flux through the material is unknown. Hence, both coefficients act as correction factors for shape effects. In a plot of $N T U(t)$ versus $F_{O}$, $a_{1}$ controls the position of the curve (and hence the magnitude of heat transfer) while $a_{2}$ controls the curvature. For calibration, standard analytical solutions provide a useful benchmark [49, 50]. A plane wall is a solid wall subjected to heating at both surfaces. When the surface heating is with a constant heat flux:

$$
a_{2}=\frac{\sqrt{\pi}}{2}
$$

And when the surface heating is with a constant temperature:

$$
a_{2}=\frac{1}{\sqrt{\pi}}
$$

where $a_{1}=0$ for both conditions. In summary, we hypothesize that, when subjected to a stepchange in surface heating, the total heat transfer through a 'breathing wall' will evolve in a similar manner to a plane wall of the same characteristic length, with slight differences due to shape effects. 


\subsubsection{Periodic heat-exchange}

What about when the exterior temperature varies periodically in a daily cycle? When a constant surface temperature or surface heat flux is applied, and after sufficient time has passed to yield a quasi steady-state, the total heat-exchange should fluctuate periodically around a steadystate mean. The behavior should approximate a semi-infinite solid, but, again, with differences due to shape effects $[49,50]$ :

$$
\begin{aligned}
& N T U(t) \\
& =N T U+a_{1} L_{c} \sqrt{\omega / \alpha} \sin (\omega t+\pi / 4)
\end{aligned}
$$

where $\omega$ is the angular frequency $(2 \pi / 86400)$. Here, the coefficient $a_{1}$ calibrates for the magnitude of the fluctuations. We hypothesize that the value for $a_{1}$ will be the same in both Equation (17) and Equation (20).

\subsection{Heat-exchange with buoyancy ventilation}

Consider the building on the left-hand side of Figure 3, operating in steady-state and without occupants. Only the integrated TAS (Thermally Active Surface) heats the room. There are no other sensible heat gains or latent heat transfer effects. Some of the heat from the TAS transfers to the room while the rest is lost to the environment by conduction:

$$
q_{0}=q_{h x}+q_{c l}
$$

where $q_{0}$ is the total heating from (both sides of) the TAS, $q_{h x}$ is the total heat-exchange to the room, and $q_{c l}$ is the total conduction loss through the envelope. The heat-exchange from the TAS to the room $\left(q_{h x}\right)$ happens in two ways. First, by transfer to the incoming air, via the heatexchanging panel. Second, by direct contact with the room air, via the exposed surface:

$$
q_{h x}=q_{1}^{\prime \prime} A_{1} \varepsilon+h A_{1}\left(T_{s}-T_{i i}\right)
$$

The new terms, $A_{1}, h$, and $T_{i i}$ are the total area of the integrated TAS, the average heat transfer coefficient between the heated surface and the room air, and the temperature of the interior air, respectively. For simplicity, assume the radiant exchanges inside the room are negligible and the interior air is well mixed.

The conduction losses $\left(q_{c l}\right)$ also happen in two ways. First, through the back of the heatexchanging panels and, second, through the parts of the building envelope that are not engaged in heat-exchange:

$$
q_{c l}=q_{1}^{\prime \prime} A_{1}(1-\varepsilon)+U A\left(T_{i i}-T_{e}\right)
$$

The term $U A$ is the total conductance $(W / K)$ of the building envelope that is not engaged in heatexchange. The heat contained in the ventilation stream can now be defined as:

$$
Q \rho c_{p}\left(T_{i i}-T_{e}\right)=q_{0}-q_{c l}
$$

where $\rho c_{p}$ is the volumetric heat capacity of air and $Q$ is the ventilation rate powered by indoor/outdoor temperature difference:

$$
Q=A^{*}\left(g Z \frac{T_{i i}-T_{e}}{T_{e}}\right)^{\frac{1}{2}}
$$


where $g$ is the gravity of Earth, $Z$ is the change in height between the flow inlet and outlet (e.g. the mid-point of the heat-exchanging panel to the top of the chimney), and $A^{*}$ is the combined effective vent area [51]

$$
A^{*}=\left(\frac{1}{2 c_{1}^{2} A_{1}^{2}}+\frac{1}{2 c_{2}^{2} A_{2}^{2}}\right)^{-\frac{1}{2}}
$$

which arises from the definition of bulk velocity:

$$
u=\frac{Q}{A^{*}}
$$

where $A_{1}$ and $A_{2}$ are the physical areas of the inlet and outlet and $c_{1}$ and $c_{2}$ are the associated discharge coefficients, respectively. For the heatexchanging panels, $A_{1}$ is the total surface area, while the discharge coefficient is:

$$
c_{1}=\left(\frac{\triangle P}{\rho u^{2} / 2}\right)^{-\frac{1}{2}}
$$

Rearranging Equation (13), the pressure drop across the heat-exchanger can be defined as:

$$
\triangle P=\frac{32 \mu L u}{D^{2} \Phi}
$$

For simplicity, assume the pressure difference along the height of the panel is uniform. Figure 3 depicts a more realistic variation in pressure due to buoyancy. Substituting Equation (29) into Equation (28) gives:

$$
c_{1}=\left(\frac{64 L \mu}{D^{2} u \rho \Phi}\right)^{-\frac{1}{2}}
$$

Finally, the discharge coefficient for the outlet, assuming it is sharp-edged, can be approximated as [51]

$$
c_{2} \approx 0.6
$$

The proceeding equations describe the essential features of the thermal coupling between 'breathing walls' and buoyancy ventilation. Looking ahead, section 4.3 reports on the results of an experimental apparatus designed to demonstrate this coupling in action. The heat-exchanging panel is installed horizontally at floor level so the pressure along the surface of the panel is uniform and the interior air is well mixed. The apparatus is the height of a room (to generate reasonable stack pressure) and is proportioned like a slender chimney. Therefore, instead of flow contraction at the outlet, there are frictional losses at the side walls to compute. After converting friction factors to discharge coefficients [52], if the flow is laminar, then:

$$
c_{2}=\frac{1}{\sqrt{64 / R e}}
$$

and if the flow is turbulent, then:

$$
c_{2}=\frac{1}{\sqrt{0.079 R e^{-0.25}}}
$$

where the Reynolds number of flow is:

$$
R e=\frac{u Z}{v}
$$

\section{Materials and methods}

Experiments were designed and executed to test the heat-exchange performance in steady and transient conditions, and when the ventilation is powered by buoyancy instead of a fan. The first experiment measures the heat-exchange in steady-state and the time to reach steady-state 
Table 2: Test panel design parameters

\begin{tabular}{lll}
\hline & Pine & Acrylic \\
\hline$k(W / m . K)$ & 0.15 & 0.19 \\
$\triangle P(P a)$ & 3 & 3 \\
$U_{0}, U_{1}, U_{2}, U_{3}\left(W / m^{2} . K\right)$ & $2.95,4.51,3.02,0.97$ & $3.74,4.90,3.17,1.32$ \\
$L, H, D(c m)$ & $5.08,6.98,0.58$ & $5.08,6.98,0.58$ \\
$\Phi$ & $0.0054(0.5 \%)$ & $0.0054(0.5 \%)$ \\
$u\left(l / s / m^{2}\right)$ & 18.7 & 18.7 \\
$\varepsilon, N T U(-)$ & $0.78,1.53$ & $0.73,1.31$ \\
\hline
\end{tabular}

when panels are subjected to a step-change in heating. The second experiment measures how the heat-exchange varies periodically with daily changes in the exterior temperature. The final experiment measures the interior temperature and flow rate inside a proxy building when the ventilation through the test panel is powered by thermal buoyancy instead of a fan.

\subsection{Test panels}

Two test panels were fabricated, one from solid wood, the other from acrylic. Southern Yellow Pine was chosen for the wood panel. Acrylic was chosen as a control, because it has similar thermal properties to wood, except the thermal properties are isotropic instead of anisotropic and it does not absorb moisture. The panels measured 12" x 16" $(30.48 \mathrm{~cm} \times 40.64 \mathrm{~cm})$ with a heat-exchange area of 12 " x 12" (30.48 cm x $30.48 \mathrm{~cm})$ and a thickness of $2^{\prime \prime}(5.08 \mathrm{~cm})$. Both panels were optimized for a design-pressure of $3 \mathrm{~Pa}$. Table 2 summarizes the properties of each panel, and they are shown side-by-side in Figure 7.

\subsubsection{Thermal properties}

The material properties needed to predict steady and transient conduction are thermal conductivity $k\left(W / m^{2} . K\right)$, thermal diffusivity $\alpha\left(\mathrm{m}^{2} / \mathrm{s}\right)$, and volumetric heat capacity $\rho c\left(J / m^{3} \cdot K\right)$. For wood, these properties depend on the species, the direction and location of measurement, and the ambient conditions. A measurement device (C-Therm Thermal Conductivity Analyzer) and the Transient Plane Source Method (ASTM D7984) was used to measure the thermal properties of Southern Yellow Pine. The samples were prepared from the same batch as the test panel and cut in radial and transverse directions to the grain. Five samples of each grain direction were prepared, each was tested ten times. The results are shown in Figure 6 in comparison with other wood species and building materials. 


\begin{tabular}{cccc}
\hline sample & $\mathrm{k}\left(\frac{\mathrm{W}}{\mathrm{mK}}\right)$ & $\alpha\left(\frac{\mathrm{m}^{2}}{\mathrm{~s}}\right)$ & $\rho \mathrm{c}\left(\frac{\mathrm{J}}{\mathrm{m}^{3} \mathrm{~K}}\right)$ \\
\hline radial cut & & & \\
A & $0.178 \pm 0.009$ & $(1.36 \pm 0.07) \cdot 10^{-7}$ & $(7.2 \pm 0.9) \cdot 10^{5}$ \\
B & $0.187 \pm 0.009$ & $(1.35 \pm 0.07) \cdot 10^{-7}$ & $(7.6 \pm 1.0) \cdot 10^{5}$ \\
C & $0.205 \pm 0.010$ & $(1.33 \pm 0.07) \cdot 10^{-7}$ & $(8.4 \pm 1.1) \cdot 10^{5}$ \\
D & $0.210 \pm 0.011$ & $(1.33 \pm 0.07) \cdot 10^{-7}$ & $(8.6 \pm 1.1) \cdot 10^{5}$ \\
E & $0.221 \pm 0.011$ & $(1.32 \pm 0.07) \cdot 10^{-7}$ & $(9.2 \pm 1.2) \cdot 10^{5}$ \\
transverse cut & & & \\
F & $0.342 \pm 0.017$ & $(1.36 \pm 0.07) \cdot 10^{-7}$ & $(1.41 \pm 0.18) \cdot 10^{6}$ \\
G & $0.327 \pm 0.016$ & $(1.32 \pm 0.07) \cdot 10^{-7}$ & $(1.36 \pm 0.17) \cdot 10^{6}$ \\
H & $0.317 \pm 0.016$ & $(1.32 \pm 0.07) \cdot 10^{-7}$ & $(1.32 \pm 0.17) \cdot 10^{6}$ \\
& & & \\
I & $0.318 \pm 0.016$ & $(1.32 \pm 0.07) \cdot 10^{-7}$ & $(1.32 \pm 0.17) \cdot 10^{6}$ \\
& $0.335 \pm 0.017$ & $(1.32 \pm 0.07) \cdot 10^{-7}$ & $(1.38 \pm 0.17) \cdot 10^{6}$
\end{tabular}
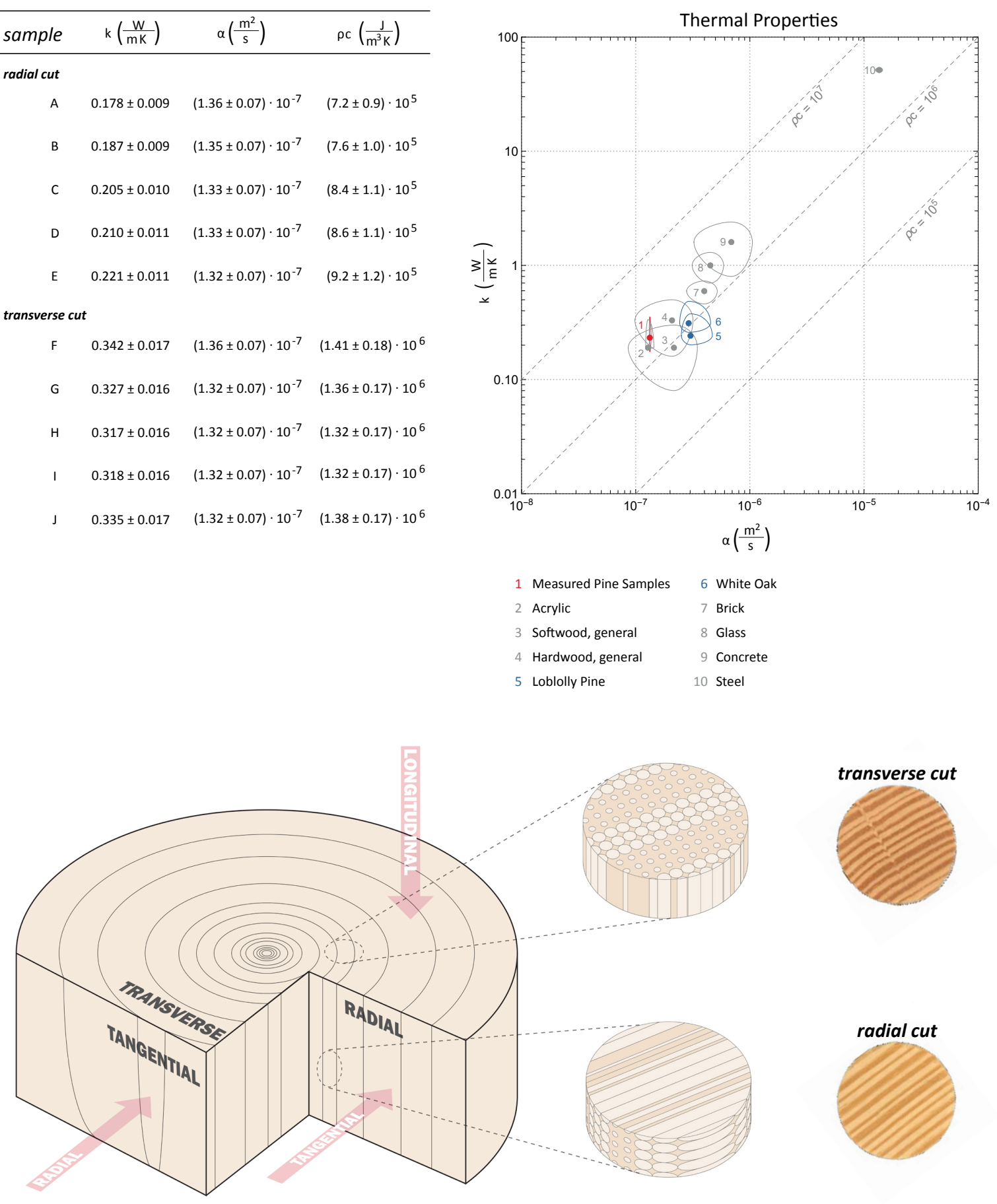

Figure 6: Thermal property measurements for Southern Yellow Pine: conductivity $(k)$, diffusivity $(\alpha)$, and volumetric heat capacity $(\rho c)$. Measurements were taken from radial and transverse samples. The data are plotted alongside other wood materials and construction materials for reference. 

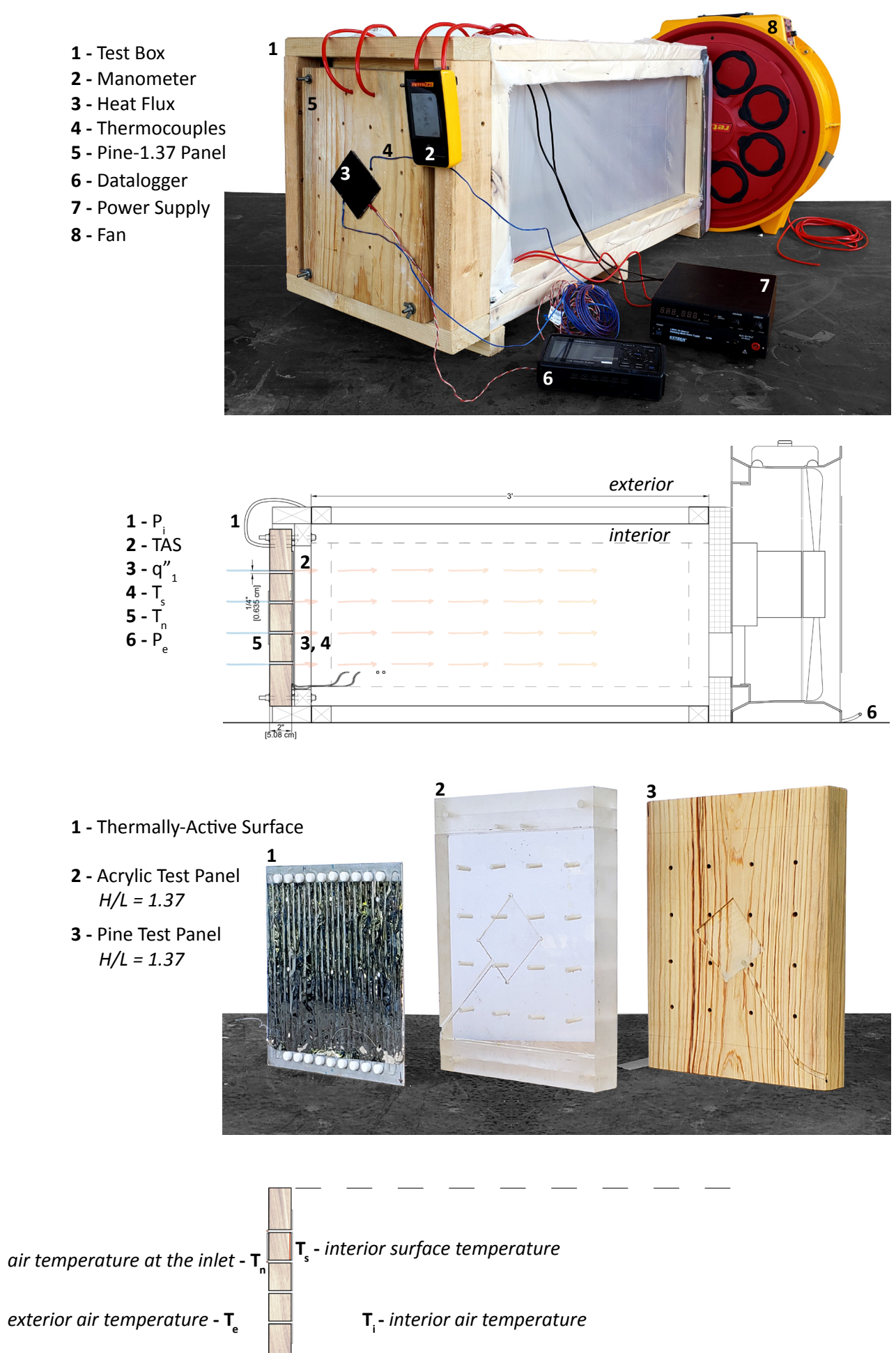

Figure 7: Experimental set-up for fan-driven ventilation 


$\begin{array}{ll}\mathbf{1}-\text { Test Box } & \mathbf{5}-\mathrm{q}_{1}^{\prime \prime} \\ \mathbf{2}-\mathrm{u} & \mathbf{6}-\mathrm{TAS} \\ \mathbf{3}-\mathrm{T}_{\mathrm{s}} & \mathbf{7}-\text { Test Panel } \\ \mathbf{4}-\mathrm{T}_{\mathrm{ii}} & \mathbf{8}-\mathrm{T}_{\mathrm{e}}\end{array}$
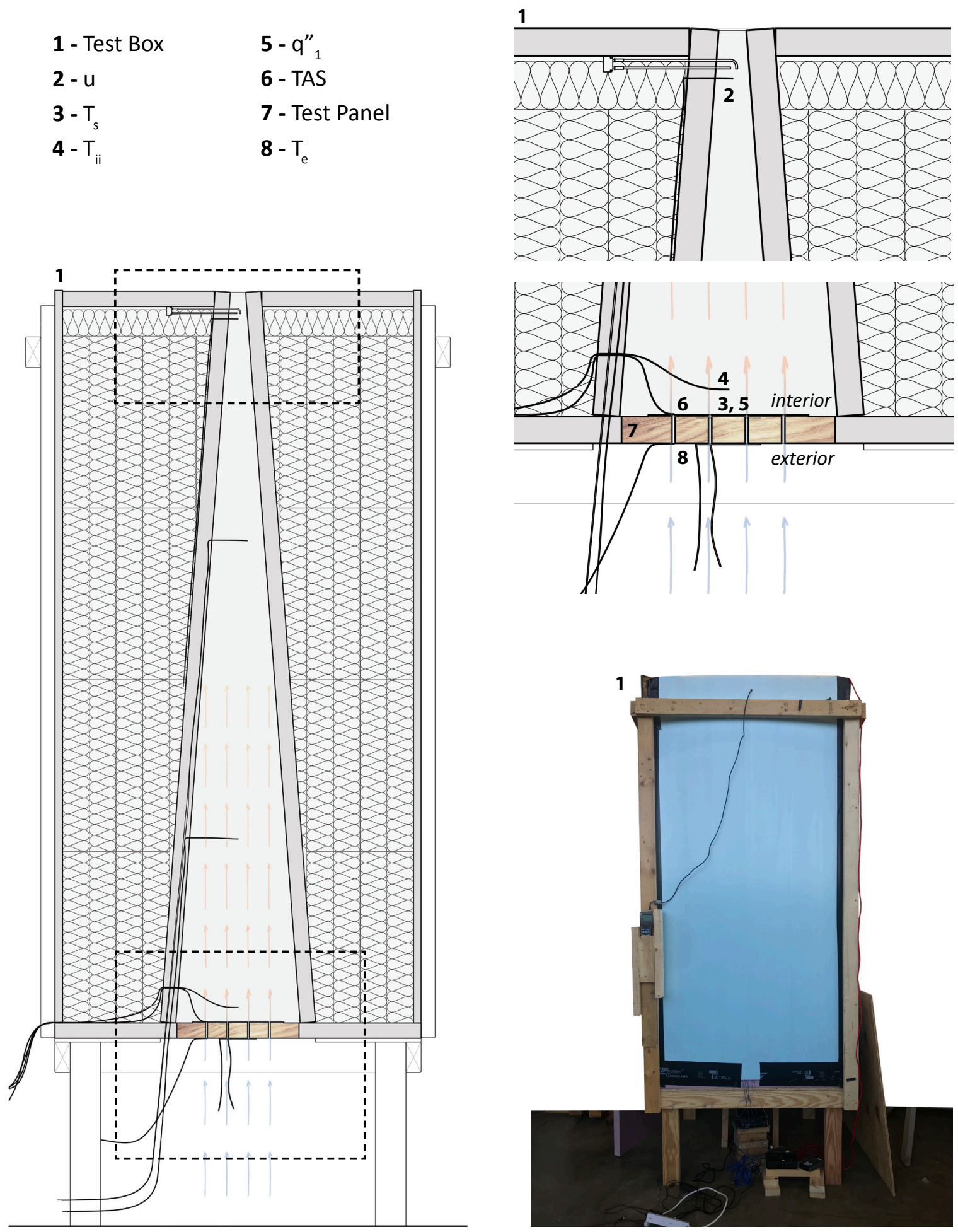

Figure 8: Experimental set-up for buoyancy-driven ventilation 


\subsubsection{Sensors}

FluxTeq Ultra 09 (85 mm x $95 \mathrm{~mm})$ sensors were used to measure the heat-flux and temperature on both surfaces of the test panels. The 'interior' heat flux sensor was placed in a routed indent so the TAS (see section 3.1.3) would fit flush to the surface. The size of the heat flux sensors determined the spacing of the channels in the panels. Air temperatures were measured using Omega Type $\mathrm{T}$ thermocouples. Temperature $T_{e}$ was measured by positioning the tip of two thermocouples over the center of two channels, then taking the average. This measurement was closely comparable to the temperature monitored outside the test box. Measurements were recorded using a GL240 data logger. The small channel made it impossible to measure $T_{i}$ with the thermocouples. When positioned over the channel, the TAS influenced the thermocouple, and inserting the thermocouple into the channel blocked the flow.

\subsubsection{Thermally-active surface}

The surface heater, referred to here as the Thermally-Active Surface (TAS), was made using electrical resistance heating wires. An array of 26 Ga Nichrome 60 was mounted to a .063" thick aluminum sheet drilled with holes to match the channels in the test panel. The wire array was wound around $1 / 4$ " tall sections of $1 / 2$ " PTFE rod. The rods were adhered to the aluminum plate at $1 "$ centers to create the $1 / 2$ " wire spacing. The wire was electrically isolated from the aluminum by a sheet of adhesive-backed polyester film. An aluminium-coated polyester film was mounted on the wire array using a spray adhesive. The TAS was divided into two parallel circuits and was connected to an Extech 600W adjustable power supply.

\subsection{Fan-driven apparatus}

This apparatus allowed air to be sucked through the test panel at constant pressure. The test chamber was made from wooden frames assembled with thin, transparent plastic sheet stretched over them (see Figure 7). Thin sheets were used so the chamber was airtight but did not accumulate heat. The joints of the chamber were sealed with caulk and a layer of tape. Attached to one end of the box was a wooden frame with a continuous gasket ring that was compressed against the edge of the test panel. Threaded rods, one at each corner, ran through the panel. Rubber washers and nuts were used to tighten the panel to the frame and compress the gasket. Mounted on the other end of the box was a piece of 2 " rigid insulation panel with a hole to accept the RetroTec 5000 series Calibrated Fan. The fan reduces pressure inside the box, simulating the interior of the building. The pressure difference was controlled and monitored by a RetroTec DM32 flow gauge and a pitot tube array. The TAS was applied to the surface of the panel facing the interior of the chamber and was controlled by an Extech 600W adjustable power supply. 


\subsubsection{Steady heat-exchange, time to steady-state}

Tests were run at the design pressure $(3 \mathrm{~Pa})$ and increasing increments of pressure (5, 7, $9 \mathrm{~Pa})$. Steady-state was defined as the point when the heat flux $\left(q_{1}^{\prime \prime}\right)$ reached $+/-5 \%$ of the target heat flux. A round of three tests was run for each pressure using the design heat flux (i.e. the heat flux optimized for $3 \mathrm{~Pa}$ ). Then another round of three tests were run for each pressure, this time increasing the heat flux incrementally as if the panel were optimized for that pressure. The difference between both methods was negligible and the results for all rounds were combined to calculate the standard error.

\subsubsection{Periodic heat-exchange}

This experiment used the same apparatus as the steady-state experiment. The test took place outdoors in a shaded location. A constant pressure $(\triangle P=3 P a)$ was maintained throughout the experiment, which ran for five days. Constant electrical power to the TAS was also maintained, so that the average heat flux was within $+/-5 \%$ of the design heat flux.

\subsection{Buoyancy-driven apparatus}

A separate chamber, acting as a proxy building, was fabricated to test the coupling with buoyancy ventilation. The heat-exchanging panel was installed horizontally at floor level to ensure the pressure across the surface of the TAS was uniform and the interior air was well mixed. (If the panel was vertical, the pressure across it would vary with height, as would the velocity and heatexchange, and there would be back-flow if the internal air stratified; these effects will be investigated in future studies). The apparatus was 8' tall $(2.44 \mathrm{~m})$, the height of a room, to generate reasonable stack pressure. The chamber was slender with a taper, like chimney, to avoid exchange flows at the top. The chamber was encased by batt and rigid insulation (see Figure 8). The test panel was mounted at the bottom of the chamber with the TAS facing the interior. A layer of tape was placed over the joint between the chamber and panel to create an airtight seal. The top opening of the chamber was $2^{\prime \prime}$ by $2^{\prime \prime}(5 \times 5 \mathrm{~cm})$. The entire assembly was mounted on legs that held the bottom of the chamber 2' $(60 \mathrm{~cm})$ off the ground. Thermocouples were located at the same positions over the channels as the fan-driven experiment, and at even intervals up the interior of the chimney. Sensirion SDP800 differential pressure sensors were attached to a pitot tube assembly to measure air velocity at the exhaust. Tests were run by incrementally increasing the heating power of the TAS. Before measurements were taken, the panel was allowed to achieve steadystate (defined in this study as when the heat-flux reaches $+/-5 \%$ of the design heat flux). 

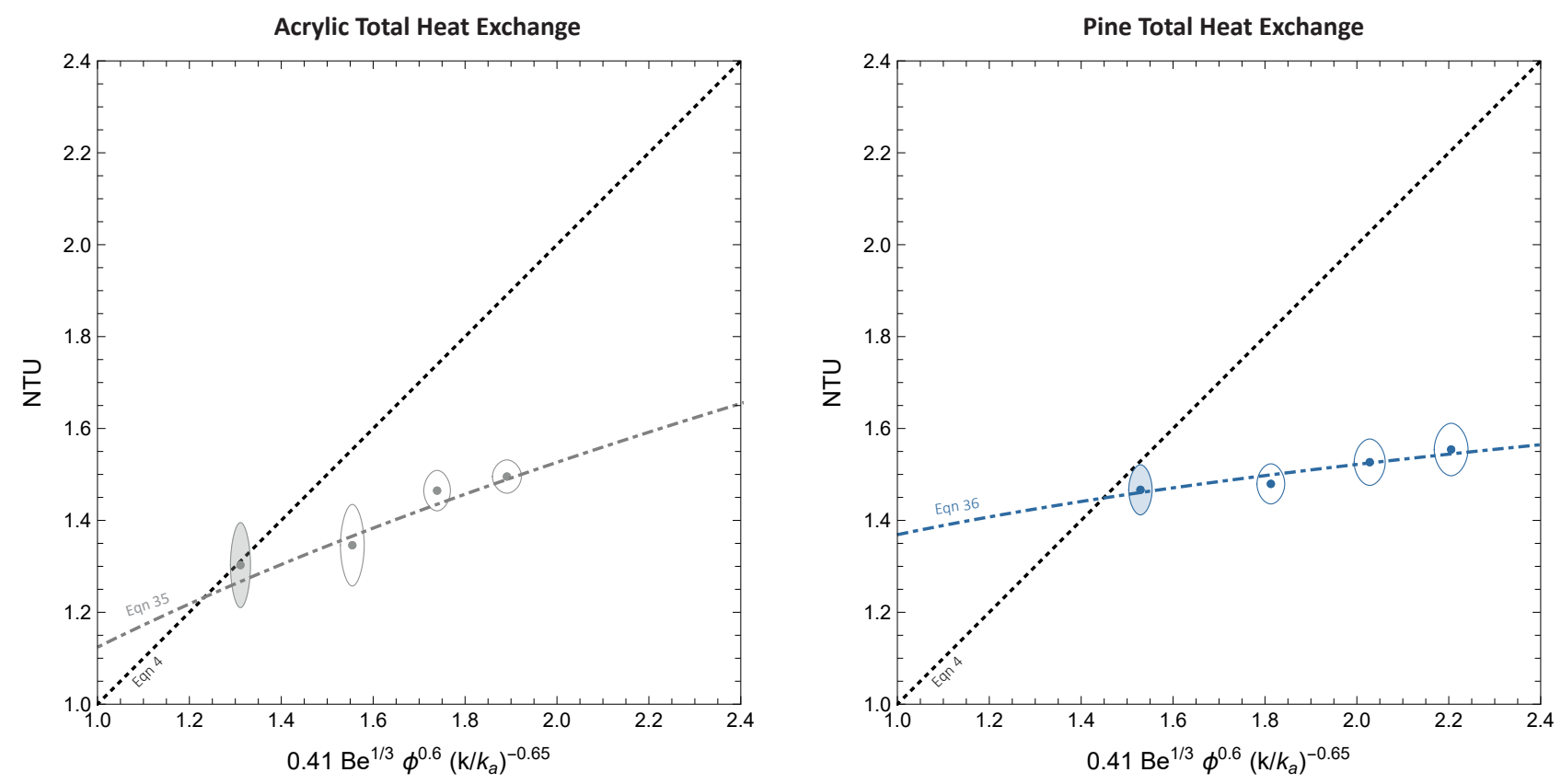

Figure 9: Measurements for steady heat-exchange

Table 3: Measurements for steady heat-exchange, pine panel

\begin{tabular}{lllllll}
\hline$\triangle P$ & $U_{1}(\mathrm{p})$ & $U_{1}$ & $\mathrm{NTU}(\mathrm{p})$ & $\mathrm{NTU}$ & $\varepsilon(\mathrm{p})$ & $\varepsilon$ \\
\hline $3 \pm 0.2$ & $4.5 \pm 0.3$ & $4.3 \pm 0.08$ & $1.5 \pm 0.03$ & $1.5 \pm 0.05$ & $0.78 \pm 0.01$ & $0.62 \pm 0.02$ \\
$5 \pm 0.2$ & - & $4.4 \pm 0.40$ & - & $1.5 \pm 0.04$ & - & $0.63 \pm 0.04$ \\
$7 \pm 0.2$ & - & $4.5 \pm 0.80$ & - & $1.5 \pm 0.05$ & - & $0.65 \pm 0.07$ \\
$9 \pm 0.2$ & - & $4.6 \pm 0.90$ & - & $1.6 \pm 0.06$ & - & $0.66 \pm 0.08$ \\
\hline
\end{tabular}

$(\mathbf{p})=$ Predicted (Equation 4)

Table 4: Measurements for steady heat-exchange, acrylic panel

\begin{tabular}{lllllll}
$\triangle P$ & $U_{1}(\mathrm{p})$ & $U_{1}$ & $\mathrm{NTU}(\mathrm{p})$ & $\mathrm{NTU}$ & $\varepsilon(\mathrm{p})$ & $\varepsilon$ \\
\hline $3 \pm 0.2$ & $4.9 \pm 0.1$ & $4.87 \pm 0.26$ & $1.3 \pm 0.02$ & $1.3 \pm 0.09$ & $0.73 \pm 0.01$ & $0.58 \pm 0.06$ \\
$5 \pm 0.2$ & - & $5.02 \pm 0.35$ & - & $1.4 \pm 0.09$ & - & $0.54 \pm 0.06$ \\
$7 \pm 0.2$ & - & $5.48 \pm 0.17$ & - & $1.5 \pm 0.04$ & - & $0.60 \pm 0.03$ \\
$9 \pm 0.2$ & - & $5.59 \pm 0.11$ & - & $1.5 \pm 0.04$ & - & $0.56 \pm 0.03$ \\
\hline
\end{tabular}

$(\mathbf{p})=$ Predicted (Equation 4) 


\section{Results and discussion}

\subsection{Steady heat-exchange}

Figure 9 shows the steady heat-exchange results for both panels. The black dotted lines represent Equation (4), while the shaded markers show measurements at the design pressure (3 Pa). From left to right, the unshaded markers show measurements at 5, 7, and 9 Pa. Tables 3 and 4 summarize the results in terms of $U_{1}$, NTU, and $\varepsilon$.

Recall that Equation (4) predicts the total heat-exchange through a panel optimized for a chosen pressure. The data represented by the shaded markers confirm the validity of Equation (4) and its pair, Equation (1). These measurements reinforce the findings of Craig and Grinham [11] and underline the robust nature of the original correlations. Kim, Lorente, and Bejan developed these correlations for extreme thermal conditions [12], so it is remarkable they transfer to building materials in ambient conditions so accurately. Note that the measurements for the wood panel at the design pressure do not match the predictions quite so well as for the acrylic panel, which acts as a control. This slight discrepancy is probably due to the anisotropic nature of wood; the grain patterns influence the heat flux as it bends towards the channels. Perhaps there is a way of exploiting this effect in further studies to improve heat-exchange.

Equation (4) only predicts the heat transfer at the design pressure. Therefore, it is no surprise that measurements at 5,7 , and $9 \mathrm{~Pa}$ deviate from Equation (4). The performance for the entire range of pressures correlated as follows for the acrylic panel:

$$
N T U_{\text {acrylic }}=1.12 N T U^{0.44}
$$

and as follows for the pine panel:

$$
N T U_{\text {pine }}=1.37 N T U^{0.15}
$$

where NTU is defined by Equations (4) and (5). As this correlation is more robust at and above the design pressure, it is used in the following two experiments. The exponents represent different slopes on the graph. Again, the differences are probably due to the anisotropic nature of wood. A gentle or flat incline for NTU, as seen in Equation (36), implies a two-state U-value. That is, a U-value that does not vary much with pressure, but which toggles between designed values of $U_{0}$ and $U_{3}$.

The total heat exchange $\left(U_{1}, q_{1} "\right.$, NTU) behaves as expected. However, Tables 3 and 4 show a mismatch between predictions and measurements for $\varepsilon$. What is the explanation? It helps to review the methods for measuring the heat-exchange efficiency, of which there are four. The first method is to measure it indirectly, having measured the NTU:

$$
\varepsilon=1-e^{-N T U}
$$

This method makes an assumption for how the heat-exchange efficiency behaves, based on stan- 
dard heat-exchanger theory. The second method measures the ratio of outgoing conduction to total heat transfer:

$$
\varepsilon=1-\frac{U_{3}}{U_{1}}=1-\frac{q_{3}{ }^{\prime \prime}}{q_{1}{ }^{\prime}}
$$

This is a direct measurement and was used in the present study. To corroborate this measurement, it is necessary to track the heat-exchange to the ventilation stream, which can be measured directly in two ways. Either:

$$
\varepsilon=\frac{U_{2}}{U_{1}}=\frac{q_{2}{ }^{\prime \prime}}{q_{1}{ }^{\prime \prime}}
$$

Or:

$$
\varepsilon=\frac{T_{i}-T_{e}}{T_{s}-T_{e}}
$$

Both methods require an accurate measurement of $T_{i}$, since $q_{2} "=u \rho c\left(T_{i}-T_{e}\right)$. However, it was not possible to measure $T_{i}$ with the current apparatus. The small diameter of the channels meant the thermocouple either blocked the channel or was influenced by the TAS (see section 3.1.2). Hence, while this experiment validates the total heat-exchange, further investigation is needed to understand what portion of heat is transferred to the incoming ventilation. Contrary to common sense, heat emanating from the exterior surface may not be entirely lost to the environment. Optical Schlieren imaging has shown that, during suction, convection multiplies at the exterior surface, while the boundary film is drawn into the channels [11]. Hence, higher than expected values for $q_{3}$ " and $U_{3}$ may be a sign of heat-recovery in action rather than increased losses. In further studies, a technique such as Background Oriented Schlieren could be used to measure $T_{i}$, so the measurements for the heat-exchange efficiency can be triangulated, and the influence of exterior film heat-recovery can be determined.

\subsection{Transient heat-exchange}

\subsubsection{Time to steady-state}

Figure 10 shows how the heat-exchange evolves with a step-change in surface heating. The data are from the pine panel, averaged over three tests at the design pressure $(3 \mathrm{~Pa})$. The electrical power heating the surface was constant throughout the experiment. The left graph shows the total heat transfer $(N T U(t))$, the right graph shows the heat-exchange efficiency $(\varepsilon)$. Both graphs track change in terms of the Fourier number, defined by Equation (15), a relative index of how conduction evolves inside an object over time. The characteristic length of the panel was $L_{c}=0.021$, calculated using Equation (16). The experiments ran for just over 240 minutes. Hence, Fo $=1$ marks approximately one hour. It also marks a significant threshold: the time at which heat supposedly penetrates the full depth of an object.

At the surface of the test panel, the heat flux $q_{1}$ " reached $+/-5 \%$ of the predicted rate after 110 minutes, when Fo 1.8. (After this point, the data were used to measure the steady heatexchange, see section 4.1). Fo 1.8 marks another 

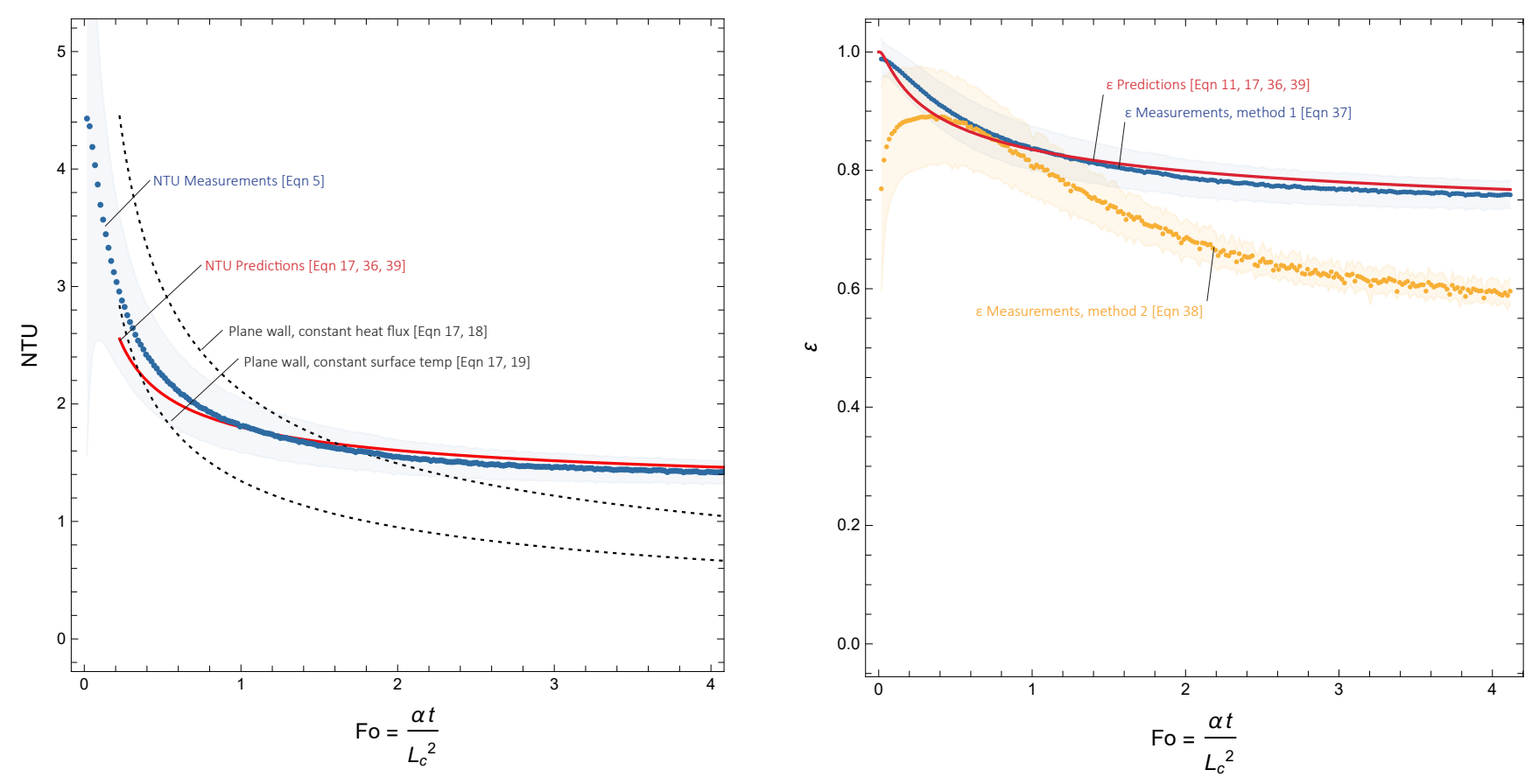

Figure 10: Pine test panel, time to steady heat-exchange (NTU, $\varepsilon)$, plotted as a function of the Fourier number. Fo $=$ 1 is approximately $1 \mathrm{hr}$.

significant moment, when the data veer outside the benchmarks, indicated by the black dotted lines. These benchmarks are the heat transfer through a plane wall of the same characteristic length during a step-change in heating, with constant temperature or constant heat flux applied at both surfaces (see Equations (17), (18) and (19)). As predicted, before steady-state is reached, the heat transfer evolves similar to a plane wall of the same characteristic length, with slight differences due to shape effects. The data for $N T U(t)$ correlate well with Equation (17) when:

$$
a_{1}=0.324
$$

and:

$$
a_{2}=0.285
$$

when Equation (36) replaces Equation (4). Recall that $a_{1}$ controls the position of the curve described by Equation (17) while $a_{2}$ controls the curvature. Further investigation is needed to establish the extent to which these shape factors for transient conduction vary with different panel dimensions, if at all. Physical experiments or finite element analysis are both valid ways of approaching this question.

The right-hand graph shows how the heatexchange efficiency changes with time, according to two methods of measuring it. As discussed, a question remains regarding the actual heat-exchange efficiency, and the additional measurements needed to confirm it. The deviating 
curve on the right-hand graph of Figure 10 may reflect enhanced heat transfer at the exterior surface due to suction. Furthermore, heat recovery at the exterior surface, due to the boundary film being sucked into the channels, may compensate the deviation between the two curves. In short, though $U_{3}$ and $q_{3}$ " are larger than expected, a significant proportion of this heat is likely recovered and not lost to the exterior environment.

\subsubsection{Periodic heat-exchange}

The pine panel was tested in shaded, outdoor conditions, using the same fan-powered apparatus as the previous experiments. Constant pressure (3Pa) and constant electrical power for heating were applied over the course of three days. The purpose of the experiment was to see if the total heat exchange would vary periodically around the steady-state value, as predicted by Equation (20). Figure 11 shows the results. Plot (i) shows the variation of temperatures $\left(T_{e}, T_{s}, T_{s}-T_{e}\right)$ over time while plot (ii) shows the variation of heattransfer coefficients $\left(U_{1}, U_{3}\right)$. Note that the baseline $\mathrm{U}$-value is $U_{0}=k / L=2.95$ (see Table 2).

Plots (i) and (ii) are included for reference, but plots (iii) and (iv) are the results of general interest, since the patterns for NTU (t) and $\varepsilon$ should be replicable in different climates with different panel designs. The total heat-exchange did behave as predicted by Equation (20), despite exposure to slight breezes and normal variations in the exterior temperature (i.e. variations that were not perfectly sinusoidal). Equation (20) includes the coefficient $a_{1}$, which accounts for shape effects and calibrates for the magnitude of heat transfer. The value for $a_{1}$ determined in the previous experiment, Equation (40), was used here. The fact that $a_{1}$ is the same in both experiments suggests it is a valid shape factor for transient conduction [50]. If this is true, it will not change significantly when the panel dimensions are different (though optimized).

The previous two experiments highlighted a discrepancy between two methods for measuring $\varepsilon$ (see Table 3 and plot (ii) of Figure 10). This discrepancy is amplified in plot (iv) of Figure 11. The data signal from measurement method 2 (Equation (38)) is lower and more volatile than measurement method 1 (Equation (37)). In Figure 11, measurement method 2, shown in plot (iv), superimposes the signals for $U_{1}$ and $U_{3}$, shown in plot (ii). Recall that higher-than-expected values for $U_{3}$ do not necessarily translate to greater losses. As discussed, further investigation is needed to measure the heat transfer to the ventilation stream (equation 39 and 40) so the boundary effects at the exterior surface and their influence on $\varepsilon$ can be fully determined.

\subsection{Heat-exchange with buoyancy ventilation}

A separate chamber, acting as a proxy building, was fabricated to test the coupling with buoyancy ventilation in steady-state. Figure 12 presents the results. Plot (i) shows the relative 

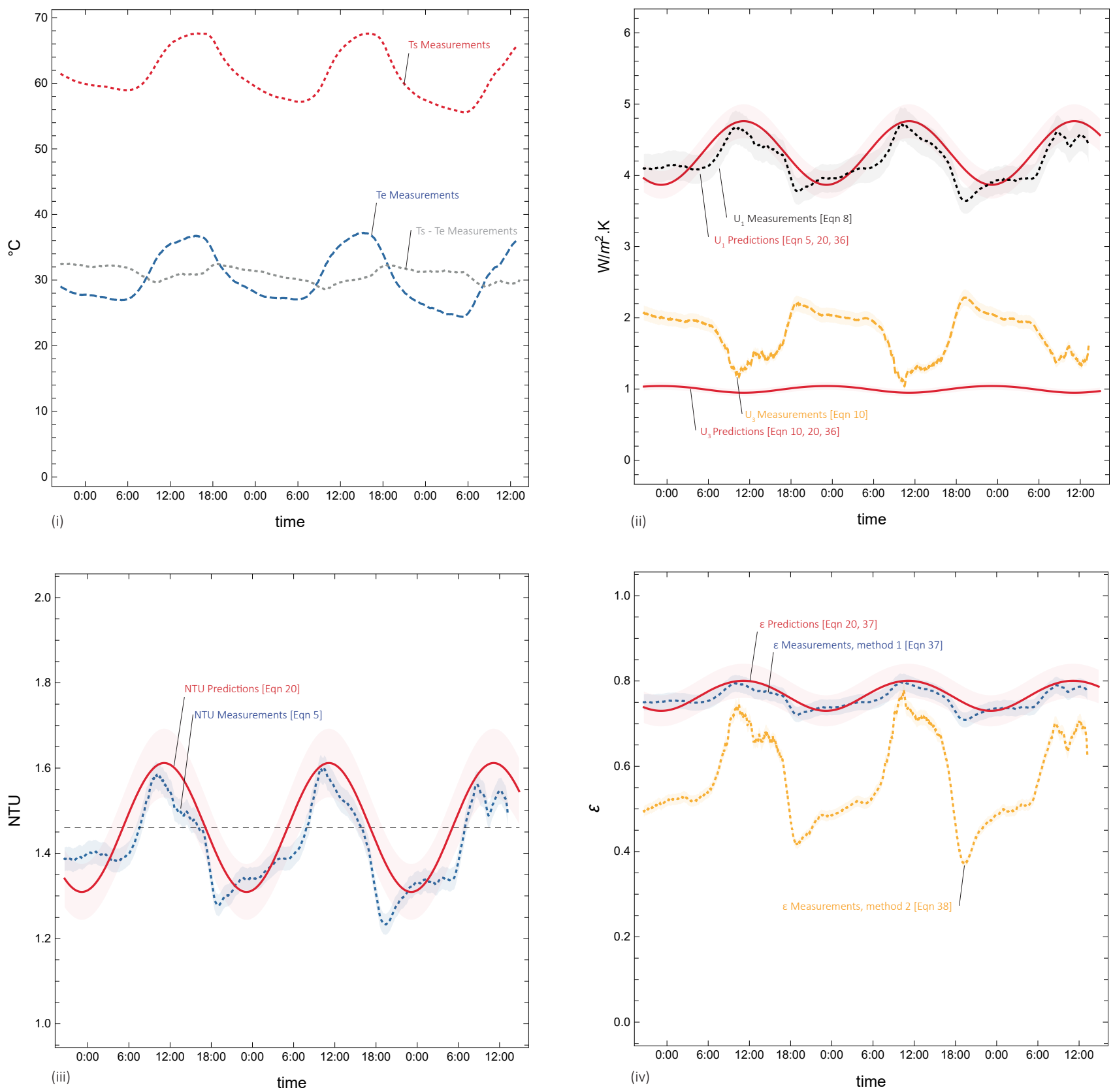

Figure 11: Periodic heat-exchange in outdoor conditions. (i) Temperatures. (ii) Heat transfer coefficients. (iii) Total heat-exchange. (iv) Heat-exchange efficiency 

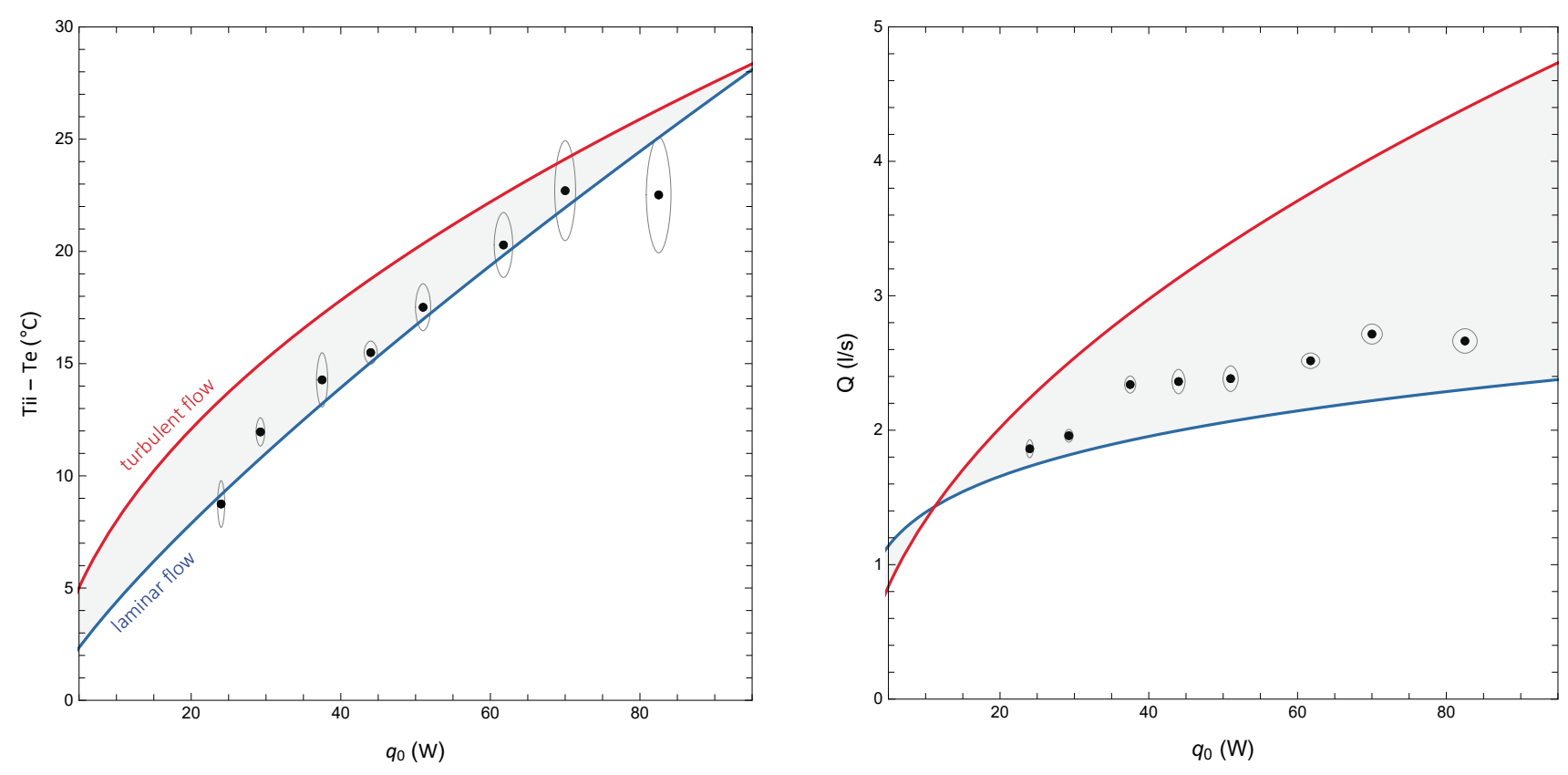

Figure 12: Coupling with buoyancy ventilation. (i) Interior temperature (relative to outdoors) and (ii) ventilation flow rate as a function of increasing heat input.

temperature of the interior $\left(T_{i i}-T_{e}\right)$ as a function of total heating from the TAS $\left(q_{0}\right)$. Plot (ii) shows the rate of buoyancy ventilation (Q), also as a function of the total heating from the TAS. The plots show two predicted curves representing laminar (blue) or fully turbulent (red) flow. These predictions were made by numerically solving the system of equations in section 2.3, where Equation (32) and Equation (33) estimate the discharge coefficient of the chimney according to either flow condition.

As the heating increases $\left(q_{0}\right)$, so too does the rate of buoyancy ventilation $(\mathrm{Q})$ and the average temperature of the interior $\left(T_{i i}\right)$. The majority of the points fall in the shaded area, validating the theory described in section 2.3 .

Notice that the measurement error for the temperature is greater than for the ventilation. The ventilation rate was measured at the narrowest point of the chimney, just below the top, where the flow converged before exiting. Temperature measurements were taken at several points up the chimney and averaged. The variation of temperature with height was not significant but the sensors did experience turbulence.

This experiment demonstrates it is possible to suck ventilation through the panels using thermal buoyancy instead of a fan, while maintaining the expected rates of heat-exchange and pressure. Further investigation is required to under- 
stand what happens when the panels are vertical (or inclined) instead of horizontal. (The pressure across a vertical panel will vary with height, as will the velocity and heat-exchange. If the internal air stratifies below the top of the panel, there will be back-flow through the channels.) Further exploration is also needed to see if there are ways to naturally recover heat from the ventilation. The right-hand side of Figure 3 shows one possible configuration.

\section{Conclusion}

This article has presented a new method for optimizing mass timber panels as heatexchangers. The results suggest a different way of building, using fewer kinds of materials, that may be better suited to the challenges of large-scale carbon removal. Test panels measured the heat-exchange in steady and transient conditions, and when the ventilation is driven by a fan or by thermal buoyancy. The total heat-exchange was predicted accurately by theory in all cases. Further details regarding the heat-exchange efficiency need investigating:

- What is the influence of convection and heat-recovery at the exterior surface?

- Do the transient conduction shape factors vary significantly with different panel dimensions? Can they be used as part of a 1D finite-difference model for higher fidelity predictions?
- What is the influence of grain-pattern, and are there orientations that improve heatexchange?

- What is the influence of moisture storage and latent heat transfer, and are there ways to exploit the effects?

The buoyancy experiment, which demonstrated that coupling is feasible, raises a parallel set of research questions:

- What happens to the ventilation and heat exchanges when the panel is vertical, that is, when the suction is non-uniform?

- Are there configurations of architectural space that allow natural heat recovery from the ventilation stream?

There are also a number of practical design and fabrication questions, which are not discussed here. This team will pursue these questions and researchers around the world are encouraged to contribute. The challenges of developing viable blueprints for mono-material buildings must be shared if progress is to be made in time for climate goals.

\section{Nomenclature}

$$
\begin{aligned}
& A_{1}, A_{2}=\text { Area of panel, vent }\left[\mathrm{m}^{2}\right] \\
& A^{*}=\text { Effective area }\left[\mathrm{m}^{2}\right] \\
& B e=\text { Bejan number }[-] \\
& B e=\text { Biot number }[-]
\end{aligned}
$$


$c_{1}, c_{2}=$ Discharge coefficient $[-]$

$c_{p}=$ Specific heat capacity $[\mathrm{J} / \mathrm{kg} \cdot \mathrm{K}]$

$D=$ Channel diameter $[m]$

$F_{o}=$ Fourier number $[-]$

$g=$ Gravity of Earth $\left[\mathrm{m} / \mathrm{s}^{2}\right]$

$H=$ Channel spacing $[m]$

$h=$ Heat transfer coefficient $\left[W / m^{2} . K\right]$

$k=$ Thermal conductivity $[W / m \cdot K]$

$L=$ Panel thickness $[m]$

$L_{c}=$ Characteristic length $[-]$

$N T U=$ Number of thermal transfer units $[-]$

$Q=$ Ventilation rate $\left[l / s, m^{3} / s\right]$

$q_{1} "=$ Heat flux, interior surface $\left[W / m^{2}\right]$

$q_{2} "=$ Ventilation heat flux $\left[\mathrm{W} / \mathrm{m}^{2}\right]$

$q_{3} "=$ Heat flux, exterior surface $\left[W / m^{2}\right]$

$q_{0}=$ Total surface heating $[W]$

$q_{c l}=$ Total conduction losses $[W]$

$q_{h x}=$ Total heat exchange $[W]$

$R e=$ Reynolds number $[-]$

$T_{e}=$ Exterior air temperature $\left[K,{ }^{\circ} C\right]$

$T_{i}=$ Temperature of incoming air $\left[K,{ }^{\circ} C\right]$

$T_{i i}=$ Interior air temperature $\left[K,{ }^{\circ} \mathrm{C}\right]$

$T_{s}=$ Interior surface temperature $\left[K,{ }^{\circ} \mathrm{C}\right]$

$t=$ Time $[s]$

$T A S=$ Thermally active surface
$Z=$ Stack height $[m]$

$\alpha=$ Thermal diffusivity $\left[\mathrm{m}^{2} / \mathrm{s}\right]$

$\Delta P=$ Pressure difference $[P a]$

$\varepsilon=$ Heat-exchange efficiency $[-]$

$\mu=$ Dynamic viscosity $[k g /(m \cdot s)]$

$\nu=$ Kinematic viscosity $\left[\mathrm{m}^{2} / \mathrm{s}\right]$

$\rho=$ Density $\left[\mathrm{kg} / \mathrm{m}^{3}\right]$

$\rho c=$ Volumetric heat capacity $\left[J / \mathrm{m}^{3} . K\right]$

$\Phi=$ Void fraction (porosity) $[-]$

$\omega=$ Angular frequency $[\mathrm{rad} / \mathrm{s}]$

\section{CRediT authorship contribution state- ment}

Salmaan Craig: Conceptualization, Methodology, Software, Formal Analysis, Resources, Data Curation, Writing - Original Draft, Writing - Review and Editing. Anna Halepaska, Jacob Elbrecht, Katherine Ferguson, Preston Rains: Software, Formal Analysis, Investigation, Data Curation, Writing - Original Draft, Writing - Review and Editing, Visualization, Project Administration. Andrew Freear: Supervision, Resources, Project Administration, Funding Acquisition, Writing - Review and Editing. David Kennedy, Kiel Moe:

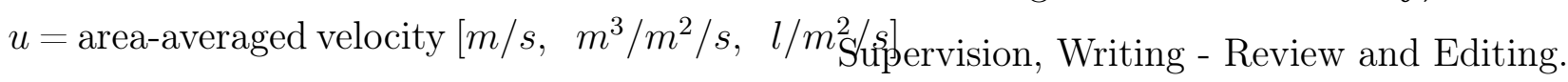
$U A=$ Total conductance $[W / K]$

$U_{0}=$ Baseline heat loss coefficient $\left[W / m^{2} . K\right]$

\section{Declaration of Competing Interest}

None

$U_{2}=$ Ventilation heat gain coefficient $\left[W / m^{2} K\right]$

$U_{3}=$ Conduction heat loss coefficient $\left[W / m^{2} K\right]$ 


\section{Acknowledgments}

Thanks to all the staff and instructors at Auburn University Rural Studio, especially Stephen Long, for providing the resources and environment to make this research possible. Also, thank you to Dr. Daniel Harris and Dr. Chandon Roy, who assisted with the thermal properties testing.

\section{References}

[1] I. E. Agency, U. N. E. Programme, 2018 Global Status Report: Towards a Zero-emission, Efficient and Resilient Buildings and Construction Sector (2018).

[2] M. Röck, M. R. M. Saade, M. Balouktsi, F. N. Rasmussen, H. Birgisdottir, R. Frischknecht, G. Habert, T. Lützkendorf, A. Passer, Embodied GHG emissions of buildings - The hidden challenge for effective climate change mitigation, Applied Energy 258 (2020) 114107. doi:10.1016/j.apenergy.2019.114107.

[3] G. Churkina, A. Organschi, C. P. O. Reyer, A. Ruff, K. Vinke, Z. Liu, B. K. Reck, T. E. Graedel, H. J. Schellnhuber, Buildings as a global carbon sink, Nature Sustainability 3 (4) (2020) 269-276. doi:10.1038/s41893-019-0462-4.

[4] C. Hepburn, E. Adlen, J. Beddington, E. A. Carter, S. Fuss, N. M. Dowell, J. C. Minx, P. Smith, C. K. Williams, The technological and economic prospects for CO 2 utilization and removal, Nature 575 (7781) (2019) 87-97. doi:10.1038/s41586-019-1681-6.

[5] C. E. Smyth, B. P. Smiley, M. Magnan, R. Birdsey, A. J. Dugan, M. Olguin, V. S. Mascorro, W. A. Kurz, Climate change mitigation in Canada's forest sector: a spatially explicit case study for two regions, Carbon Balance and Management 13 (September 2018). doi:10.1186/s13021-018-0099-z.
[6] J. Seppälä, T. Heinonen, T. Pukkala, A. Kilpeläinen, T. Mattila, T. Myllyviita, A. Asikainen, H. Peltola, Effect of increased wood harvesting and utilization on required greenhouse gas displacement factors of wood-based products and fuels, Journal of Environmental Management 247 (2019) 580-587. doi:10.1016/j.jenvman.2019.06.031.

[7] E. Hurmekoski, T. Myllyviita, J. Seppälä, T. Heinonen, A. Kilpeläinen, T. Pukkala, T. Mattila, L. Hetemäki, A. Asikainen, H. Peltola, Impact of structural changes in wood-using industries on net carbon emissions in Finland, Journal of Industrial Ecology n/a (n/a). doi:10.1111/jiec.12981.

[8] A. Bejan, I. Dincer, S. Lorente, A. Miguel, H. Reis, Porous and Complex Flow Structures in Modern Technologies, Springer-Verlag, New York, 2004. doi:10.1007/978-1-4757-4221-3.

[9] Architectured Materials in Nature and Engineering: Archimats, Springer International Publishing, 2019. doi:10.1007/978-3-030-11942-3.

[10] H. Wu, A. Liew, T. V. Mele, P. Block, Analysis and optimisation of a rib-stiffened vaulted floor for dynamic performance, Engineering Structures 213 (2020) 110577. doi:10.1016/j.engstruct.2020.110577.

[11] S. Craig, J. Grinham, Breathing walls: The design of porous materials for heat exchange and decentralized ventilation, Energy and Buildings 149 (2017) 246259. doi:10.1016/j.enbuild.2017.05.036.

[12] S. Kim, S. Lorente, A. Bejan, Vascularized materials with heating from one side and coolant forced from the other side, International Journal of Heat and Mass Transfer 50 (17) (2007) 3498-3506. doi:10.1016/j.ijheatmasstransfer.2007.01.020.

[13] H. Bartussek, Porenluftung, eine zugfreie Stalluftung, DLZ (1981).

[14] A. Dalehaug, A. Fukushima, H. Yoshinori, Dynamic Insulation in a Wall, Report Collection of Architectural Institute of Japan no. 66 (1993). 
[15] B. J. Taylor, D. A. Cawthorne, M. S. Imbabi, Analytical investigation of the steady-state behaviour of dynamic and diffusive building envelopes, Building and Environment 31 (6) (1996) 519-525, internalpdf://157/Taylor et al. - 1996 - Analytical investigation of the steady-state behav.pdf. doi:10.1016/03601323(96)00022-4.

[16] B. J. Taylor, M. S. Imbabi, The effect of air film thermal resistance on the behaviour of dynamic insulation, Building and Environment 32 (5) (1997) 397404, internal-pdf://90/Taylor and Imbabi - 1997 The effect of air film thermal resistance on the b.p df. doi:10.1016/S0360-1323(97)00012-7.

[17] B. J. Taylor, R. Webster, M. S. Imbabi, The building envelope as an air filter, Building and Environment 34 (3) (1998) 353-361, internal-pdf://160/Taylor et al. - 1998 - The building envelope as an air filter.pdf. doi:10.1016/S0360-1323(98)00017-1.

[18] B. J. Taylor, M. S. Imbabi, Dynamic insulation in multistorey buildings:, Building Services Engineering Research and Technology (1999). doi:10.1177/014362449902000403.

[19] B. J. Taylor, M. S. Imbabi, Environmental design using dynamic insulation, ASHRAE Transactions 106 (January 2000).

[20] M. Krarti, Effect of Air Flow on Heat Transfer in Walls, Journal of Solar Energy Engineering 116 (1) (1994) 35-42. doi:10.1115/1.2930063.

[21] A. Alongi, L. Mazzarella, Characterization of Fibrous Insulating Materials in their Application in Dynamic Insulation Technology, Energy Procedia 78 (2015) 537-542, internal-pdf://134/Alongi and Mazzarella 2015 - Characterization of Fibrous Insulating Materials i.pdf. doi:10.1016/j.egypro.2015.11.732.

[22] A. Alongi, L. Mazzarella, The Dual Air Vented Thermal Box: A Laboratory Apparatus to Test Air Permeable Building Envelope Technologies, Energy Procedia 78 (2015) 1543-1548, internal-
pdf://183/Alongi and Mazzarella - 2015 - The Dual Air Vented Thermal Box A Laboratory Appa.pdf. doi:10.1016/j.egypro.2015.11.198.

[23] A. Alongi, A. Angelotti, L. Mazzarella, Analytical modelling of Breathing Walls: experimental verification by means of the Dual Air Vented Thermal Box lab facility, Energy Procedia 140 (2017) 36-47. doi:10.1016/j.egypro.2017.11.121.

[24] A. Alongi, A. Angelotti, L. Mazzarella, Experimental investigation of the steady state behaviour of Breathing Walls by means of a novel laboratory apparatus, Building and Environment 123, internal-pdf://38/Alongi et al. - 2017 - Experimental investigation of the steady state beh.pdf (2017). doi:10.1016/j.buildenv.2017.07.013.

[25] A. Alongi, A. Angelotti, L. Mazzarella, Experimental validation of a steady periodic analytical model for Breathing Walls, Building and Environment 168 (2020) 106509. doi:10.1016/j.buildenv.2019.106509.

[26] J. Wang, Q. Du, C. Zhang, X. Xu, W. Gang, Mechanism and preliminary performance analysis of exhaust air insulation for building envelope wall, Energy and Buildings 173 (2018) 516-529. doi:10.1016/j.enbuild.2018.05.045.

[27] C. Zhang, W. Gang, X. Xu, L. Li, J. Wang, Modelling, experimental test, and design of an active air permeable wall by utilizing the low-grade exhaust air, Applied Energy 240 (2019) 730-743. doi:10.1016/j.apenergy.2019.02.087.

[28] C. Zhang, J. Wang, L. Li, W. Gang, Dynamic thermal performance and parametric analysis of a heat recovery building envelope based on airpermeable porous materials, Energy 189 (2019) 116361. doi:10.1016/j.energy.2019.116361.

[29] B. Park, W. V. Srubar, M. Krarti, Energy performance analysis of variable thermal resistance envelopes in residential buildings, Energy and Buildings 103 (2015) 317-325. 
doi:10.1016/j.enbuild.2015.06.061.

[30] K. Menyhart, M. Krarti, Potential energy savings from deployment of Dynamic Insulation Materials for US residential buildings, Building and Environment 114 (2017) 203-218. doi:10.1016/j.buildenv.2016.12.009.

[31] V. Shekar, M. Krarti, Control strategies for dynamic insulation materials applied to commercial buildings, Energy and Buildings 154 (2017) 305-320. doi:10.1016/j.enbuild.2017.08.084.

[32] S. Rupp, M. Krarti, Analysis of multi-step control strategies for dynamic insulation systems, Energy and Buildings 204 (2019) 109459. doi:10.1016/j.enbuild.2019.109459.

[33] M. Dabbagh, M. Krarti, Evaluation of the performance for a dynamic insulation system suitable for switchable building envelope, Energy and Buildings 222 (2020) 110025. doi:10.1016/j.enbuild.2020.110025.

[34] A. H. A. Dehwah, M. Krarti, Impact of switchable roof insulation on energy performance of US residential buildings, Building and Environment 177 (2020) 106882. doi:10.1016/j.buildenv.2020.106882.

[35] K.-N. Rhee, K. W. Kim, A 50 year review of basic and applied research in radiant heating and cooling systems for the built environment, Building and Environment 91 (2015) 166-190. doi:10.1016/j.buildenv.2015.03.040.

[36] K.-N. Rhee, B. W. Olesen, K. W. Kim, Ten questions about radiant heating and cooling systems, Building and Environment 112 (2017) 367-381. doi:10.1016/j.buildenv.2016.11.030.

[37] K. Moe, Thermally Active Surfaces in Architecture, Princeton Architectural Press, 2010.

[38] F. Meggers, V. Ritter, P. Goffin, M. Baetschmann, H. Leibundgut, Low exergy building systems implementation, Energy 41 (1) (2012) 48-55. doi:10.1016/j.energy.2011.07.031.
[39] X. Lim, The super-cool materials that send heat to space, Nature 577 (7788) (2019) 18-20. doi:10.1038/d41586-019-03911-8.

[40] C. Kiamili, A. Hollberg, G. Habert, Detailed Assessment of Embodied Carbon of HVAC Systems for a New Office Building Based on BIM, Sustainability 12 (8) (2020) 3372. doi:10.3390/su12083372.

[41] A. W. Woods, S. Fitzgerald, S. Livermore, A comparison of winter pre-heating requirements for natural displacement and natural mixing ventilation, Energy and Buildings 41 (12) (2009) 1306-1312. doi:10.1016/j.enbuild.2009.07.030.

[42] D. W. Etheridge, J. J. Zhang, Dynamic insulation and natural ventilation: Feasibility study, Building Services Engineering Research and Technology 19 (4) (1998) 203-212. doi:10.1177/014362449801900403.

[43] F. Ascione, N. Bianco, C. D. Stasio, G. M. Mauro, G. P. Vanoli, Dynamic insulation of the building envelope: Numerical modeling under transient conditions and coupling with nocturnal free cooling, Applied Thermal Engineering 84 (2015) 114, internal-pdf://176/Ascione et al. - 2015 - Dynamic insulation of the building envelope Numer.p df. doi:10.1016/j.applthermaleng.2015.03.039.

[44] K.-S. Park, S.-W. Kim, S.-H. Yoon, Application of Breathing Architectural Members to the Natural Ventilation of a Passive Solar House, Energies 9 (3) (2016) 214, internal-pdf://178/Park et al. - 2016 - Application of Breathing Architectural Members to .pdf. doi:10.3390/en9030214.

[45] S. Craig, R. Fortin, Design of Mass Timber Panels as Heat Exchangers, Wolfram Demonstrations Project (July 10, 2020).

URL https://demonstrations.wolfram.com/ DesignOfMassTimberPanelsAsHeatExchangers/

[46] P. Carrer, P. Wargocki, A. Fanetti, W. Bischof, E. D. O. Fernandes, T. Hartmann, S. Kephalopoulos, S. Palkonen, O. Seppänen, What does the sci- 
entific literature tell us about the ventilation-health relationship in public and residential buildings?, Building and Environment 94 (2015) 273-286. doi:10.1016/j.buildenv.2015.08.011.

[47] S. Kim, S. Lorente, A. Bejan, Dendritic vascularization for countering intense heating from the side, International Journal of Heat and Mass Transfer 51 (25) (2008) 5877-5886.

[48] S. Kim, S. Lorente, A. Bejan, Transient behavior of vascularized walls exposed to sudden heating, International Journal of Thermal Sciences 48 (11) (2009) 2046-2052. doi:10.1016/j.ijthermalsci.2009.03.019.

[49] F. Incropera, D. DeWitt, T. L. Bergman, A. S. Lavine, Fundamentals of Heat and Mass Transfer, 6th Edition, John Wiley \& Sons, 2007.

[50] G. C. J. Bart, K. Hanjalić, Estimation of shape factor for transient conduction, International Journal of Refrigeration 26 (3) (2003) 360-367. doi:10.1016/S01407007(02)00079-8.

[51] A. Acred, Natural ventilation in multi-storey buildings: a preliminary design approach (2014). doi: $10.25560 / 34322$.

[52] B. M. Jones, M. J. Cook, S. D. Fitzgerald, C. R. Iddon, A review of ventilation opening area terminology (2016). doi:10/254154. 